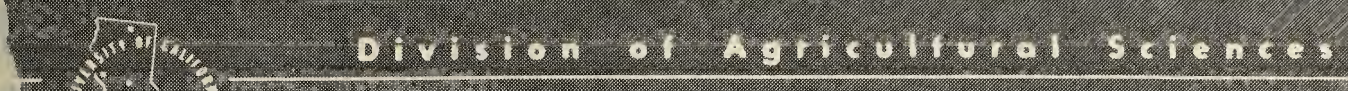

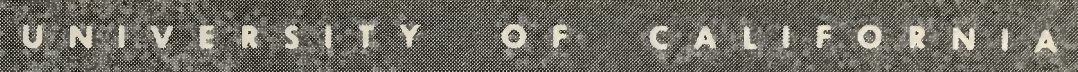

\title{
PROPAGATION
}

of temperate-zone

\section{fruit plants}

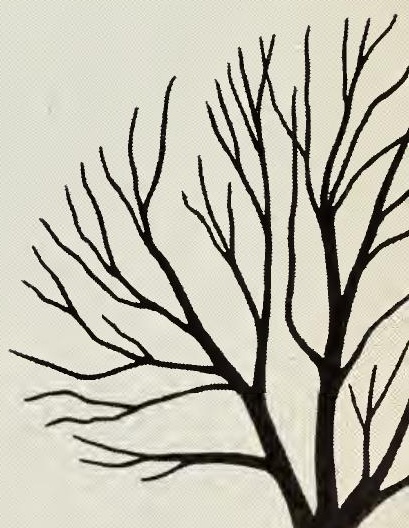

C. J. HANSEN - H. T. HARTMANN 
The commercial fruit grower who wishes to apply the principles of propagation by budding and grafting in his orchards will find the necessary instructions in this circular. He will also find information on the propagation of fruit plants by cuttings, layering, suckers, and runners, The material should also be of interest to the nurseryman and to the home gardener.

This publication supersedes a portion of Extension Circular 96.

A

B

E

O

Selecting rootstocks

Almonds

Apples

Apricots

Cherries

Fig

Grapes

Olives

Peaches and nectarines .................... 7

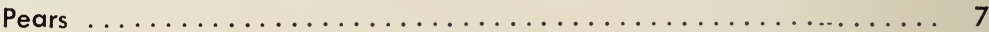

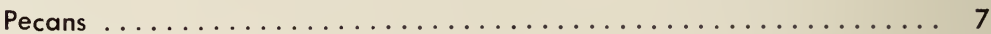

Persimmons .......................... 7

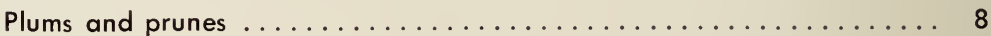

Walnuts ............................. 8

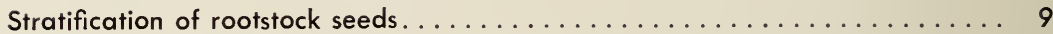

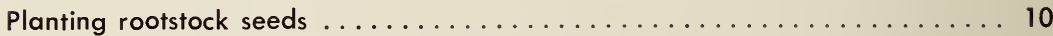

Vegetative methods of propagation ........................ 11

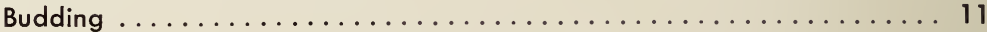

Late-summer or fall budding in the nursery $\ldots \ldots \ldots \ldots \ldots \ldots \ldots 11$

June budding in the nursery $\ldots \ldots \ldots \ldots \ldots \ldots \ldots \ldots \ldots \ldots$

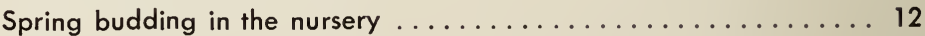

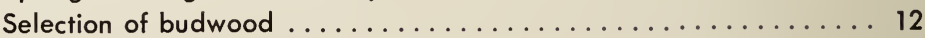

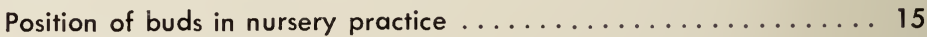

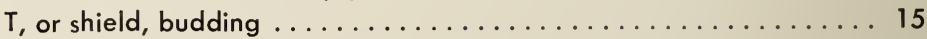

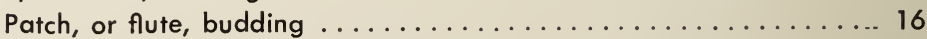

Hinge, $I$, or modified $\mathrm{H}$ budding ................ 18

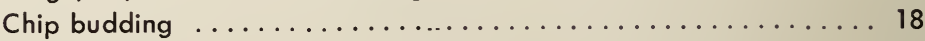

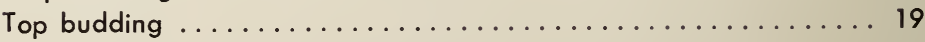

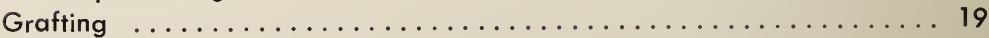

Selection and storage of scion wood $\ldots \ldots \ldots \ldots \ldots \ldots \ldots \ldots$

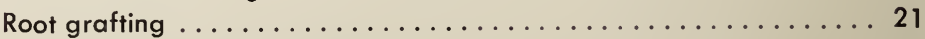

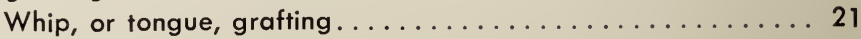

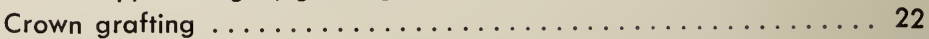

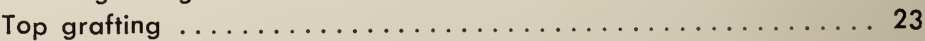


The fruits and nuts grown in California may be divided into two general groups: 1) temperate-zone fruits, chiefly deciduous, produced in both the northern and southern parts of the state; and 2) subtropical fruits which, while not limited to the southern area, are better suited to its warmer climate. This circular is concerned only with the propagation of temperate-zone fruits.

$\begin{array}{llllllll}C & O & N & T & E & N & T & S\end{array}$

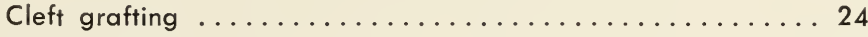

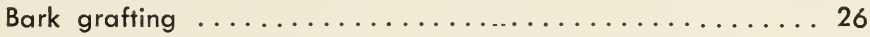

Saw-kerf, or notch, grafting ................ 30

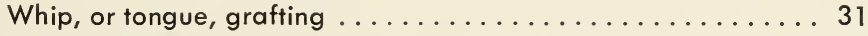

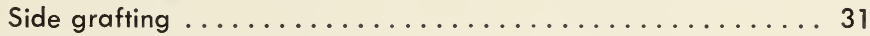

Subsequent treatment of topworked trees ............ 32

Bridge grafting ............................ 34

Inarching ................................ 35

Grades of nursery trees ........................ 37

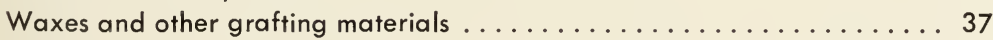

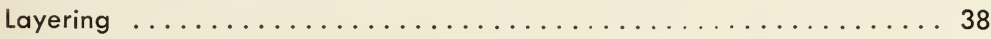

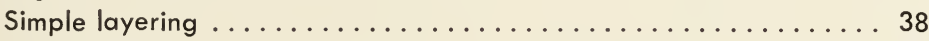

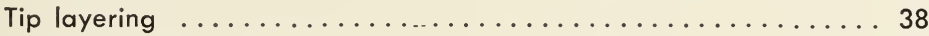

Mound, or stool, layering ...................... 39

Trench layering ................................ 39

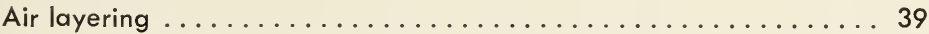

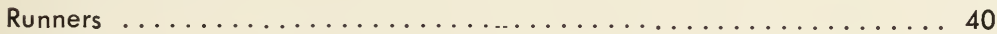

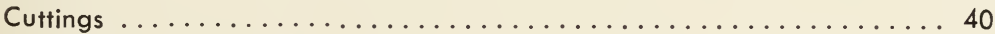

Hardwood cuttings ........................ 41

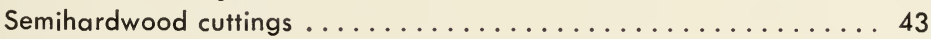

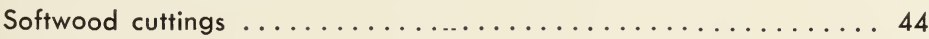

Root cuttings ............................ . 44

Leaf-bud cuttings ..................... 45

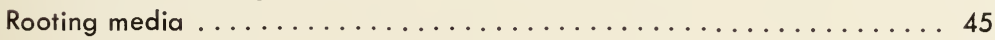

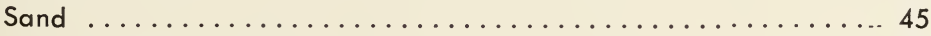

Sand-peat moss mixture ................... 45

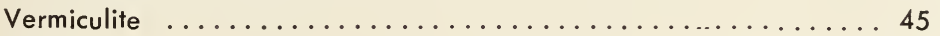

Perlite ........................... 45

Mist propagation for leafy cuttings .................. 45

Use of growth regulators in rooting cuttings .............. 48

Powder dip method ....................... 48

Dilute solution, 24 -hour soaking method .............. 49

Concentrated-solution dip method ................ 49

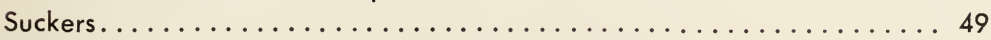

Methods of propagating various fruit plants $\ldots \ldots \ldots \ldots \ldots \ldots \ldots \ldots \ldots \ldots \ldots \ldots$ 


\section{J. HANSEN}

$P_{L}$ eral ways: by seeds and by vegetative propagation. As a rule, the use of seeds in the propagation of fruit varieties, although simple and economical, is not satisfactory; the seedlings produced are usually different from the parents, especially in size, shape, and quality of the fruit. In addition, the various seedlings are likely to differ from one another. This great variation, although undesirable to the plant propagator, is a valuable aid to the breeder who is trying to produce better plants. Fruit varieties that would come reasonably true from seed could be obtained by selection and breeding over several plant generations, but since each generation requires a number of years, the time necessary would be prohibitive. The fruit-plant propagator must therefore use a vegetative method - that is, he must root some part of the parent plant, such as stem or root (cuttings, layering, and similar processes), or must place a part of one plant on another in such a way that it will grow (grafting and budding). Since, in vegetative propagation, a portion of the parent plant is simply growing in a different location, a plant so propagated will ordinarily be identical with the parent.

Placing a piece of branch-a section a

\section{H. T. HARTMANN}

few inches long-in soil or in sand so that it will form roots and new branches is not difficult or expensive. This method - propagation by cuttings - is used for the quince, fig, pomegranate, grape, olive, currant, gooseberry, and certain other fruits. Unfortunately, some of the principal tree fruits (for example, pears, apples, cherries, peaches, apricots, almonds, walnuts, and most plums) are so difficult to propagate by cuttings or similar methods that these procedures cannot be followed economically. Such plants, therefore, are usually propagated by first growing seedlings and then budding or grafting the desired variety upon them. The plants upon which fruit varieties are budded or grafted are called rootstocks. Seedlings are usually uniform enough for this purpose, but vegetatively propagated plants are sometimes used to secure such benefits as disease resistance and uniform vigor.

Many additional varieties would be propagated on their own roots by cuttings or similar methods if this procedure were possible or economical. Sometimes, however, it would not be desirable. For example, certain rootstocks now available are more resistant to nematodes, diseases, or adverse soil conditions than are the varieties on their own roots.

\section{THE AUTHORS:}

C. J. Hansen is Professor of Pomology and Pomologist in the Experiment Station, Davis.

H. T. Hartmann is Associate Professor of Pomology and Associate Pomologist in the Experiment Station, Davis. 


\section{SELECTING ROOTSTOCKS}

The rootstocks in use are discussed below, and some information is given concerning the source of seed.

Almonds. The principal rootstocks for the almond are almond and peach. Almond seed is sometimes obtained from bitter almond seedlings, but usually from commercial sweet almond varieties, such as the Texas. The choice between peach and almond as a rootstock depends upon the experience of growers in the district where the trees will be planted, but if root-knot nematodes are present in the soil, a nematode-resistant peach rootstock should be selected. Additional information concerning peach rootstocks will be found in the section on peaches and nectarines. Myrobalan plum (Prunus cerasifera) has been tried as a rootstock for almonds, but it is usually not commercially satisfactory.

Marianna 2623 and Marianna 2624, which are selected types of Marianna plum $(P$. cerasifera $\mathrm{x} P$. munsoniana $[?])$, have been used to a limited extent as rootstocks for almonds in heavy, wet soils and in areas infected with oak root fungus (Armillaria mellea). Both are propagated by means of hardwood cutings. Ne Plus Ultra, Texas, Peerless, Jordanolo, and in most cases IXL are making satisfactory growth on these stocks, although considerable overgrowth usually occurs at the union. Nonpareil and Drake, on the other hand, nearly always make unsatisfactory growth on either Marianna 2623 or 2624. Some recent plantings of a new variety, Davey, on Marianna 2624 have also been unsatisfactory. The ultimate size of these almond varieties on plum roots is not known, but observations during the first 14 to 17 years indicate that they will be relatively smaller than trees on almond or peach roots. Marianna 2623 and 2624 are both satisfactory for heavy, wet soils. Marianna 2624 is more resistant to oak root fungus than is Marianna 2623, but it should not be considered to be immune. Growing almond trees on plum roots involves some risk because the ultimate behavior of the tree is not known. However, that risk is probably justified if the use of these rootstocks is restricted to wet areas in orchards or in areas infected with oak root fungus.

Apples. In the past, rootstocks for apples have been grown to a great extent from "French crab" seed, obtained mostly from France. The French crab trees are principally seedlings whose fruit is used for cider. In recent years, however, seed of domestic commercial varieties has been used in large quantities, accounting at present for almost the entire United States supply of rootstocks for apples. The nurseries that grow most of the apple rootstocks for California, Oregon, and Washington obtain the seed chiefly from such varieties as Winesap, Rome Beauty, Delicious, Stayman Winesap, and Yellow Newtown. Jonathan seed is also used, although some nurserymen think that the seedlings obtained are not completely satisfactory. A number of agricultural experiment stations have tested the ability of the seed of many commercial varieties to germinate and to produce desirable seedlings. Most of the stations are satisfied with the seed of Rome Beauty, Delicious, Ben Davis, Whitney, and Winesap. On the other hand, they do not recommend the seed of Baldwin, Rhode Island Greening, and Gravenstein.

If dwarf apple trees are desired, the grower may use certain types of Paradise rootstock, which can be propagated by layers and root cuttings. He may also 
obtain dwarf trees by using a standard rootstock with an intermediate stem piece of a dwarfing variety such as Clark Dwarf.

The East Malling Research Station in England has sorted out and tested the various strains of Paradise and similar stocks. Each of these bears the name Malling, followed by a number. The one best known in the United States is Malling IX, a dwarfing stock suitable for gardens. Some of the semidwarfing types are being tested in this country for possible commercial value, but work is still experimental.

Apricots. The chief rootstocks for the apricot are apricot and peach. Blenheim or Royal apricot seeds, easily obtained from drying yards and canneries, are commonly used. If root-knot nematodes are likely to be present, the grower should probably choose apricot root. It is, however, more subject to gopher injury than is peach. Myrobalan plum, although not used extensively, should probably be chosen for heavy soils that tend to be wet. Apricot trees on myrobalan root, however, have not been wholly satisfactory. A small percentage has been broken at the graft union by heavy winds, and die-back has sometimes occurred.

Recent trials indicate that Marianna 2623 and Marianna 2624 plums may be used in place of myrobalan as apricot rootstocks in soils that are too heavy or wet for apricot or peach roots. However, most of the apricot trees growing on these roots are less than 17 years old, and additional testing will be required before it can be known whether they are entirely satisfactory. Both these rootstocks have also been used in areas infected with oak root fungus, but Marianna 2624 is considered the more resistant. Since some Marianna 2624 roots have been killed by oak root fungus, it will still require a number of years to determine whether this rootstock has enough resistance to justify its continued use for this purpose.
Both Marianna 2623 and 2624 are propagated by means of hardwood cuttings.

Cherries. Mazzard (sweet cherry) and mahaleb are the common rootstocks for sweet cherries. Of these, the mahaleb gives the trees more resistance to buckskin disease and drought, but is more subject to root-knot nematode and gopher injury.

A sour cherry, the Stockton Morello, has been used somewhat for adapting sweet cherries to heavy, shallow, or wet soils. Although this rootstock is considered commercially satisfactory, Chapman and a few of the less important varieties sometimes do not do well on it. The most noticeable effect of the rootstock is a definite dwarfing of the sweet cherry top. Suckers, which Stockton Morello usually produces in abundance, are generally considered the most practicable means of propagation. However, recent experiments have shown that this rootstock may also be propagated by means of softwood cuttings under mist. Use of this rootstock is not advisable, however, unless virus-free stock is available. Seedlings of Stockton Morello should not be used due to their variability.

Figs. No special rootstocks are used for the fig. The trees are propagated by means of hardwood cuttings, and are therefore on their own roots.

Grapes. If neither root-knot nematodes nor phylloxera is present in the soil, grape vines may be propagated by hardwood cuttings and thus be on their own roots. In those areas where the soil is infested with root-knot nematodes, the usual rootstock used is Solonis x Othello 1613. However, if phylloxera is the principal problem, Rupestris St. George would be the best rootstock to use. These resistant rootstocks are all propagated by means of hardwood cuttings.

Olives. Since olive varieties can be propagated by cuttings, the trees are often grown on their own roots; they can also be budded or grafted on various 
rootstocks. Of the varieties grown in California, Mission and Manzanillo produce strong, fruitful trees on their own roots, but Sevillano trees started from cuttings are slow-growing and somewhat dwarfed. Cuttings of Sevillano are difficult to root while those of Mission and Manzanillo root readily. Seedlings of the Mission and Redding Picholine varieties are sometimes used as rootstocks for all the major varieties, especially Sevillano, but the resulting trees are quite variable in vigor and growth habit. A more suitable rootstock, giving uniform trees, would be rooted cuttings of a stronggrowing variety, such as Mission.

Peaches and nectarines. The peach and the nectarine are propagated almost entirely on peach seedlings grown from seed of commercial varieties, principally Lovell, and from seed of special rootstock selections, such as S-37 and Shalil. Although apricot seedlings are sometimes employed in sandy soils to resist root-knot nematode injury, the union is not always successful.

Lovell seedlings are seriously injured by both species of root-knot nematodes known to cause trouble in California orchards, and should be used only in those areas where nematodes are not a problem. Seedlings of S-37 and Shalil are immune or highly resistant to one of the species of root-knot nematodes (Meloidogyne incognita var. acrita) commonly found in California peach orchards, but only partially resistant to the other $(M$. javanica). Since Shalil is known to be somewhat susceptible to crown rot, it would seem best to use S-37 in nematodeinfested soils until a completely resistant rootstock is found.

Pears. The French pear (Pyrus communis) is the usual rootstock for pears. In the past, the seed has come largely from Europe, but recently almost all of it has been obtained from American canneries. Most of the seed is from the Bartlett variety, the principal canning pear. However, a limited amount of Winter
Nelis seed has also been used. Old Home (a blight-resistant variety) may be used for the framework branches with French pear seedlings as the rootstock. Even a severe blight infection would not affect the resistant framework, on which a new top could later be built.

In California, the Japanese pear, Pyrus pyrifolia ( $P$. serotina), has been an unsatisfactory rootstock because of black-end trouble. Black end is also produced by $P$. ussuriensis, another Oriental species. Only a slight amount of black end has been found in orchards on $P$. calleryana root, and the trees showing the trouble are possibly replants, not on true $P$. calleryana. However, since this Oriental species does not have a clear record with respect to black end, it may well be avoided even though it is more blight-resistant than either French pear or quince.

If dwarf trees are desired, quince root is used. Since the Bartlett variety does not make a good union directly with quince, it is necessary to double-work with Hardy (Beurre Hardy) - that is, use a short piece of Hardy stem between the quince root and the Bartlett top. Old Home trees grafted directly on quince root have made satisfactory growth for 16 years. This evidence suggests that quince root, blight-resistant Old Home framework, and Bartlett top may be used without the Hardy intermediate.

Pecans. Seedlings grown from nuts taken either from seedling trees or from commercial pecan varieties are used as rootstocks.

Persimmons. Seedlings of three Diospyros species-D. lotus, D. kaki, and D. virginiana - can be used as rootstocks for varieties of the Oriental persimmon, D. kaki.

D. lotus seedlings are vigorous, drought-resistant, and produce a rather fibrous type of root system which transplants easily. This stock is quite susceptible to crown gall, however, and does not 
tolerate poorly drained soils. The Hachiya variety does not produce well on $D$. lotus stock because of excessive fruit shedding. Scions of the Fuyu variety are reported to make a poor union with this stock.

D. kaki is probably the best stock for general use, although the seedlings are difficult to transplant because they have a long taproot with few laterals. This stock makes a good union with all varieties; the trees grow well and yield satisfactory commercial crops. Seeds for rootstock use may be obtained from any of the Oriental persimmon varieties that produce seeds.

D. virginiana seedlings are favored as a rootstock in the southern part of the United States. Most Oriental persimmon varieties make a good union with this stock, which is tolerant of excess soil moisture and produces a desirable fibrous type of root system. In California, however, the Hachiya variety on this stock is distinctly dwarfed and yields poorly because of sparse bloom.

Plums and prunes. One important rootstock for plums and prunes is the myrobalan plum (Prunus cerasifera). The seeds are usually obtained from trees growing in California. Peach is the other important rootstock; nearly all varieties do well on it. Almond, which has been used to some extent, is satisfactory with many varieties, provided the soil conditions are suitable for it. Many varieties do well on apricot root, which is sometimes used in soils infested with root-knot nematodes, but the plums discussed below are now preferred.

Recently there has been considerable interest in selected types of myrobalan and Marianna ( $P$. cerasifera $\times$ P. munsoniana [?]) plums that may be propagated by hardwood cuttings. One such myrobalan plum rootstock, Myrobalan 29 , grows vigorously and is not injured by root-knot nematodes. Although it is a little more resistant to oak root fungus than are most seedling myrobalan plums, a considerable proportion of trees have died when planted in infected soils. A vigorous Marianna selection (Marianna 2624) appears to withstand oak root fungus better than do other plum roots thus far tested. Since some Marianna 2624 roots have been killed by oak root fungus, it will still require a number of years to determine whether this rootstock has enough resistance to justify its continued use for this purpose. It is not injured by root-knot nematodes.

Myrobalan or one of the other types of plum rootstock should be used in soil that is heavy and tends to be wet during part of the year.

Walnuts. Northern California black walnut (Juglans hindsii) seedlings have been the standard rootstock for Persian (English) (J. regia) walnut plantings in California for the past 50 years. They are vigorous enough in good valley soils suitable for walnut production. The seedlings are highly resistant to oak root fungus, but not immune, so that an occasional tree is killed. They are susceptible to crown rot and root-lesion nematode (Pratylenchus vulnus).

Paradox hybrid seedlings, resulting from natural crosses of Northern California black and Persian walnuts, have been used in increasing numbers during the past few years. On the average, they have shown greater vigor than Northern California black walnut in foothill soils. or valley soils not of the best quality, and in replant situations. They will withstand fluctuating water table conditions better than Northern California black walnut, and are highly resistant to crown rot. In addition, they are partially resistant to root-lesion nematode.

Persian walnut seedlings have been used in a few instances where crown rot is a serious problem but where oak root fungus is known not to be present. 


\section{STRATIFICATION OF ROOTSTOCK SEEDS}

When removed from the plant, the seeds of most deciduous fruit trees ordinarily will not germinate, even under ideal conditions of moisture and temperature. This is caused partially by the fact that the seed embryos are in a rest which must be broken by cold. In addition, the seeds of many plants are covered with a stony layer which must be softened before germination begins. The usual method of breaking the rest and softening the hard coat is to put the seed in a cool place between alternate layers of moist sand or other materials, such as a mixture of sand and peat moss. This treatment, called stratification, is begun in the fall or winter, depending upon the kind of tree. The seeds remain in the stratifying medium until planted in the nursery. As a general rule, stratification should continue until the embryonic root is seen starting to push through the seed covering. The seeds should then be planted immediately. Some species do not require a stratification period for germination.

It is advisable, with most seeds, to soak them in water for about 24 hours before they are put into the stratification material.

The size of container (fig. 1) used for stratification depends upon the quantity of seed to be treated, and may vary from that of a polyethylene bag or a small box to a large pit in the ground. The seeds illustrated are in layers because that is the easiest way to place them in the box. Slightly better results might be obtained by mixing the seeds and sand thoroughly so that each seed would be surrounded by a maximum amount of sand, but most nurserymen do not consider this step

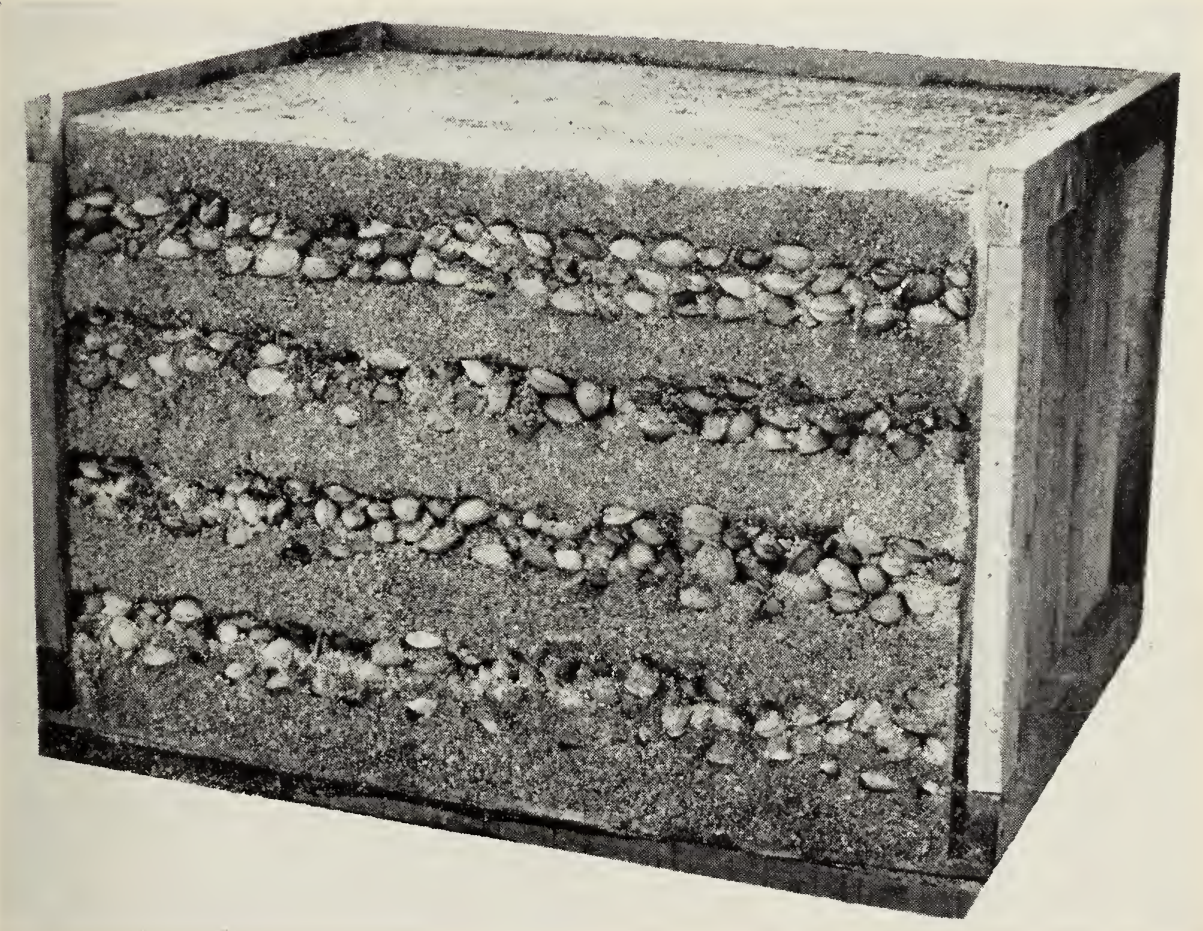

Fig. 1. Side of box has been removed to show how seed of deciduous fruits may be stratified in moist sand. 
necessary. The stratifying medium must be kept moist; it is desirable to check the seeds at intervals during this period and add water if necessary. Take care to avoid an excessive amount of moisture. Airtight containers must not be used as aeration is necessary during the stratification process. If necessary, cover the boxes or pits with wire screen for protection against birds or rodents.

Better germination may be expected with some seeds if they are stratified in cold storage at temperatures of $32^{\circ}$ to $40^{\circ} \mathrm{F}$, rather than in outdoor pits, especially when the winters are warm. The following are suggested stratification periods at $32^{\circ}$ to $40^{\circ} \mathrm{F}$ :

$\begin{array}{cc}20 \text { to } 30 \text { days: } & 90 \text { to } 120 \text { days: } \\ \text { Almond } & \text { Cherry } \\ \text { Apricot } & \text { Peach } \\ 60 \text { to } 90 \text { days : } & \text { Plum } \\ \text { Apple } & \text { Walnut } \\ \text { Pear } & \end{array}$

\section{PLANTING ROOTSTOCK SEEDS}

There are two methods of planting fruit tree seeds: (1) directly in the nursery row after the stratification period is complete, with the resulting seedlings budded the same year; (2) thickly in a seedbed, with the seedlings moved to the nursery row the following winter or early spring. The second method produces trees with roots one year older than those produced by the first method. For either method, the planting is usually done in February or early March. Details of procedure and the rootstocks involved are discussed below.

The rootstock seeds that are planted directly in the nursery row after stratification are apricot, almond, peach, wal. nut, pecan, and sometimes myrobalan plum and mahaleb cherry. (Since the tops of pecan seedlings grow rather slowly, it is usually necessary to delay budding or grafting until the second year.) The rows are usually 4 feet apart, with seeds planted about 4 inches apart in the row. If experience has shown that certain kinds of seed tend to germinate poorly, the grower may decide to plant them much closer than 4 inches and to thin later if necessary. The large walnut seeds are usually placed 4 to 5 inches deep; the medium-sized apricot, almond, peach, and pecan, about 3 inches; and the smaller myrobalan plum about $11 / 2$ inches. To prevent drying out, seeds are usually planted deeper in light than in heavy soils, but this precaution may not be necessary if irrigation water is available at all times. In a few instances seeds have been planted directly in the nursery row in the fall, without stratification. This method is not common, however, because it is difficult to maintain favorable moisture conditions in the field, rodents may destroy many seeds, and the weeds that grow during the winter may be difficult to remove without disturbing the seeds.

The rootstock seeds that are grown one season in a seedbed and then transplanted to the nursery row are apple, pear, mazzard cherry, and sometimes myrobalan plum and mahaleb cherry. The type of seedbed varies considerably, but the commercial producers of seedling trees generally plant in rows far enough apart for the convenient use of horse- or tractordrawn cultivators. A stand of 10 to 15 seedlings per foot is usually needed to keep the trees from growing too large for satisfactory transplanting. If large numbers of seedlings are not required, the seed may be broadcast or planted in rows in beds of convenient size. The apple and pear seeds are planted about 1 inch deep, and the cherry and myrobalan plum seeds about $11 \frac{1}{2}$ inches. Immediately after being transplanted to the nursery row, the larger seedlings should be cut back to approximately 8 or 10 inches above the ground. It is usually not necessary to prune those with tops less than 8 or 10 inches long. To expedite planting, the lateral roots are usually cut back to stubs a few inches long. 
The chief vegetative methods of propagation for deciduous fruits, discussed in the following pages, are budding, grafting, layering, and the use of cuttings, suckers, and runners. Often plants may be propagated by more than one of these methods. The nurseryman knows, from experience, how to secure the most plants for the least outlay in cost and materials. A fruit grower, however, may sometimes use a method that would not be practical on a large scale.

\section{BUDDING}

Budding is the placing of a single detached bud upon a plant called the stock. This method is used by the nurseryman to propagate his plants and sometimes by the grower to change trees over to another variety. Some of the names given to methods of budding are based on the time of year in which the work is done. Spring budding is usually done in March or April, June budding in May or the first half of June, and late-summer or fall budding in July and August or a little later. Other names used are based on the method of cutting and inserting the bud, such as shield budding, patch budding, I budding, chip budding, and other, less important methods. In all these processes, success depends upon joining the cambiums of the stock and the bud. The cambium, or growing layer, is found between the wood and the bark.

Late-summer or fall budding in the nursery. Budding, although usually done in July and August, may be continued into September and October until the bark cannot be lifted. The budwood is collected from the current season's growth at the time the work is done, but may be stored a short while if kept cool and moist. The buds are either placed in trees that have grown from seeds planted in the spring of the same year, or, with apples, pears, and sometimes cherries and myrobalan plums, in trees lined out in the nursery row in the spring. About the time growth starts in the spring after budding, cut back the top of the seedling rootstock to about $5 / 8$ inch above the bud (that is, just above the crosscut of the T, or top of the patch). Usually this cut slopes downward from the side where the bud is located. Remove all water sprouts appearing below the bud. The trees are dug in the winter after the buds have grown one season.

Trees thus produced will have either two- or three-year-old roots and oneyear-old tops. They are, however, called one-year-old, or yearling, trees; the age of the roots is not considered. Two-yearold deciduous fruit trees (that is, trees with two-year-old tops) are not usually offered for sale in California.

Late-summer or fall budding is the most important method used for deciduous fruit trees, although in recent years June budding has been used considerably to propagate some kinds of fruit trees.

June budding in the nursery. If advance orders and inquiries indicate that the supply of fall-budded trees will not meet the demand, and if the seedling trees have grown sufficiently in the three or four months since planting, June budding may be done in May or in the first half of June. Some nurseries have made it a regular practice to propagate a considerable number of trees by this method.

The usual procedure is to cut off the seedling top 2 to 5 inches above the bud three or four days after budding. Leave 
at least one leaf above the bud, and several below. It may be necessary to bud as much as 8 inches above the ground in order to have a sufficient number of leaves below the bud. These rootstock leaves help to manufacture food for the tree until the leaves produced by the bud are large enough to take over this function. Make a cut back to the bud 10 to 16 days after budding. Thereafter, any shoots other than those from the bud should be shortened, and when the bud has grown into a shoot 6 to 8 inches high and has enough leaves of its own, remove all other leaves and shoots.

The budwood is collected from the current season's growth at the time of budding. As a rule, all the wood is removed from the bud shield except a small core in the bud. The easiest way to do this is to make the long cut, as shown in figure $2, \mathrm{~A}$, and then, at the upper end, to make a cut through the bark only, rather than through both bark and wood. The shield may then be removed with a sliding motion, and the wood remains attached to the bud stick. If the shield is pulled rather than slid from the bud stick, the small core of wood may become separated from the bud itself, and the result often is failure. Given ideal growing conditions, a medium-sized tree suitable for the orchard will be obtained by the time growth stops in the fall; and thus a year will be gained. Though the method described is relatively simple, heavy losses are likely to occur unless the work is carefully done.

Seedlings must grow rapidly in order to be large enough for budding in May or in the first half of June. Because the peach best meets this requirement, most June-budded trees offered for sale are on this rootstock. Nurserymen list various varieties of June-budded peaches, nectarines, almonds, apricots, and plums. June-budding generally is feasible only in regions which have a long growing season.
Spring budding in the nursery. The work is begun early in spring, as soon as the bark of the stock slips easily from the wood and allows the buds to be inserted, and should be completed before the trees have made much new growth. This will usually be in March or April, depending on the kinds of trees and the season. As a rule, the bud sticks are collected in late winter, while dormant, and are stored in moist sphagnum moss, peat moss, or sand, in a cool place. They can be used for T, or shield, budding without further treatment.

For patch budding, however, the bud sticks must be transferred to a warm location and kept there until the bark will slip from the wood. By that time a few buds will have started to grow. These cannot be used, but others will be in good condition. Bud sticks for patch budding may also be cut directly from the tree at the time of budding, a practice thought by many to be the best. When this method is used, bud sticks on which part of the buds have started to grow are cut from the trees. Some buds will be in the right condition, that is, they will still be almost completely dormant, and yet the bark of the patches can be separated from the wood of the bud sticks-a requirement of patch budding.

About two weeks after budding, the tops of the stocks are cut off to force the buds into growth. The next winter, after the buds have grown one season, the trees are dug and sold. They are then essentially the same as the one-year-old trees produced by late-summer or fall budding.

This method is usually less satisfactory than late-summer or fall budding, and should be used only for trees that were not successfully budded during the fall, or in some other special cases.

Selection of budwood. Buds for latesummer or fall budding and June budding should be taken from the current season's growth of the specified tree at 
the time of budding, but for work in the spring, dormant branches are usually selected and stored until needed. Although it is probably best to choose bud sticks that have leaf buds (wood buds) only, many propagators use clusters containing both leaf and flower (fruit) buds. Do not use flower buds exclusively, because these blossom and die. In plums, apricots, peaches, and walnuts, a leaf bud usually occurs at each node or joint, either alone or associated with one or more flower buds. A single flower bud is occasionally found on the bud sticks of these species, but not often enough to cause the propagator much concern. Leaf buds are usually smaller and sharper- pointed than flower buds. Pear, apple, and almond bud sticks often have a number of single flower buds near the apical end. (In the pear and apple, these are really mixed buds, but usually respond the same as ordinary flower buds.) Since the apical end is customarily discarded because of its small size, the danger of using these undesirable buds is minimized.

The sweet cherry is most likely to cause trouble because its flower buds are located on the basal part of the shoots (fig. 3 ), a part which the propagator is likely to use if he does not know the position of the buds. The matter is further complicated by the fact that cherry flower buds
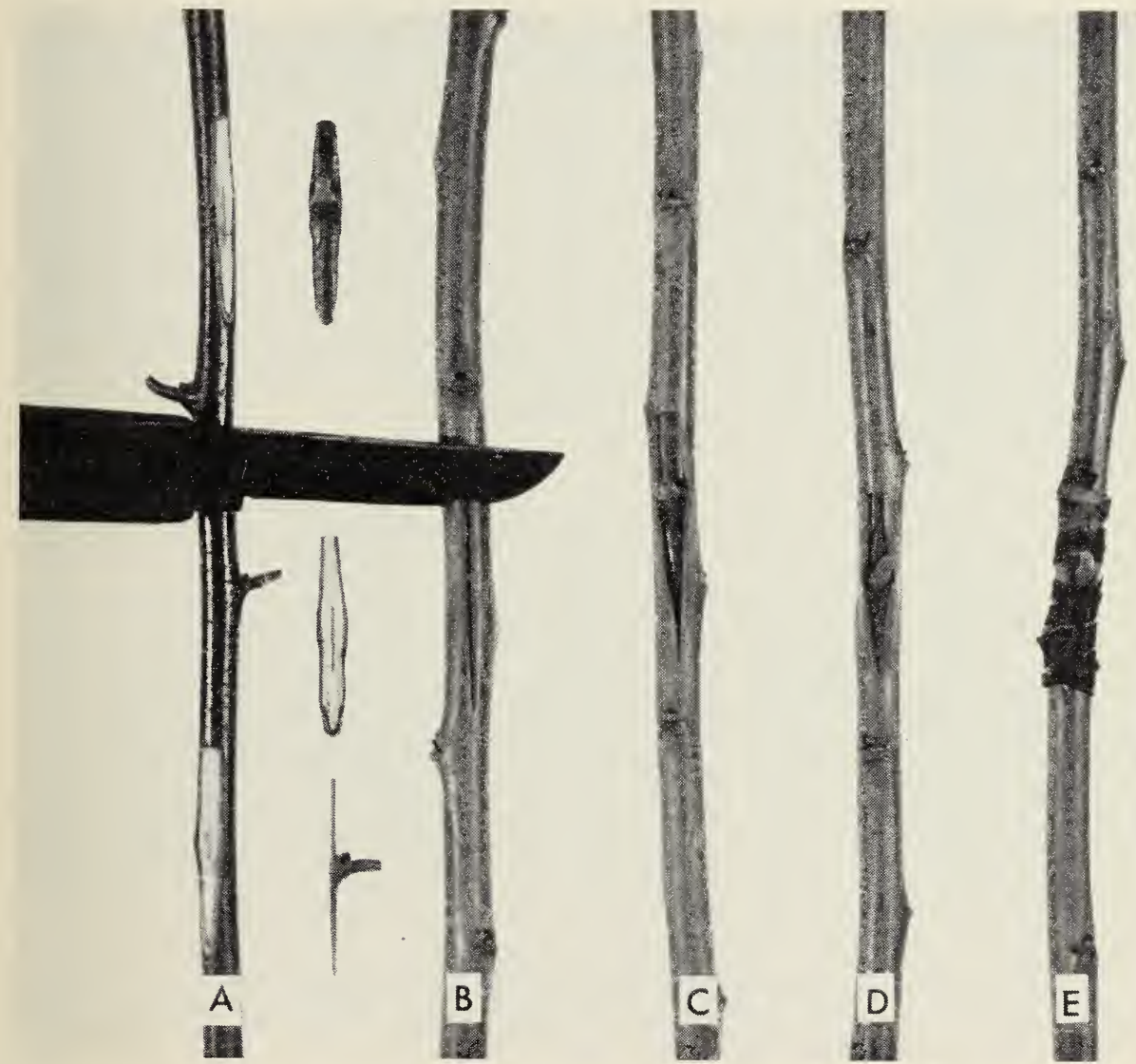

Fig. 2. T, or shield, budding. A, bud stick with some buds removed (cuts should be started below buds); B, making crosscut at top of vertical slit; $C$, bud partly inserted; D, bud in place; $E$, bud tied with budding rubber. 

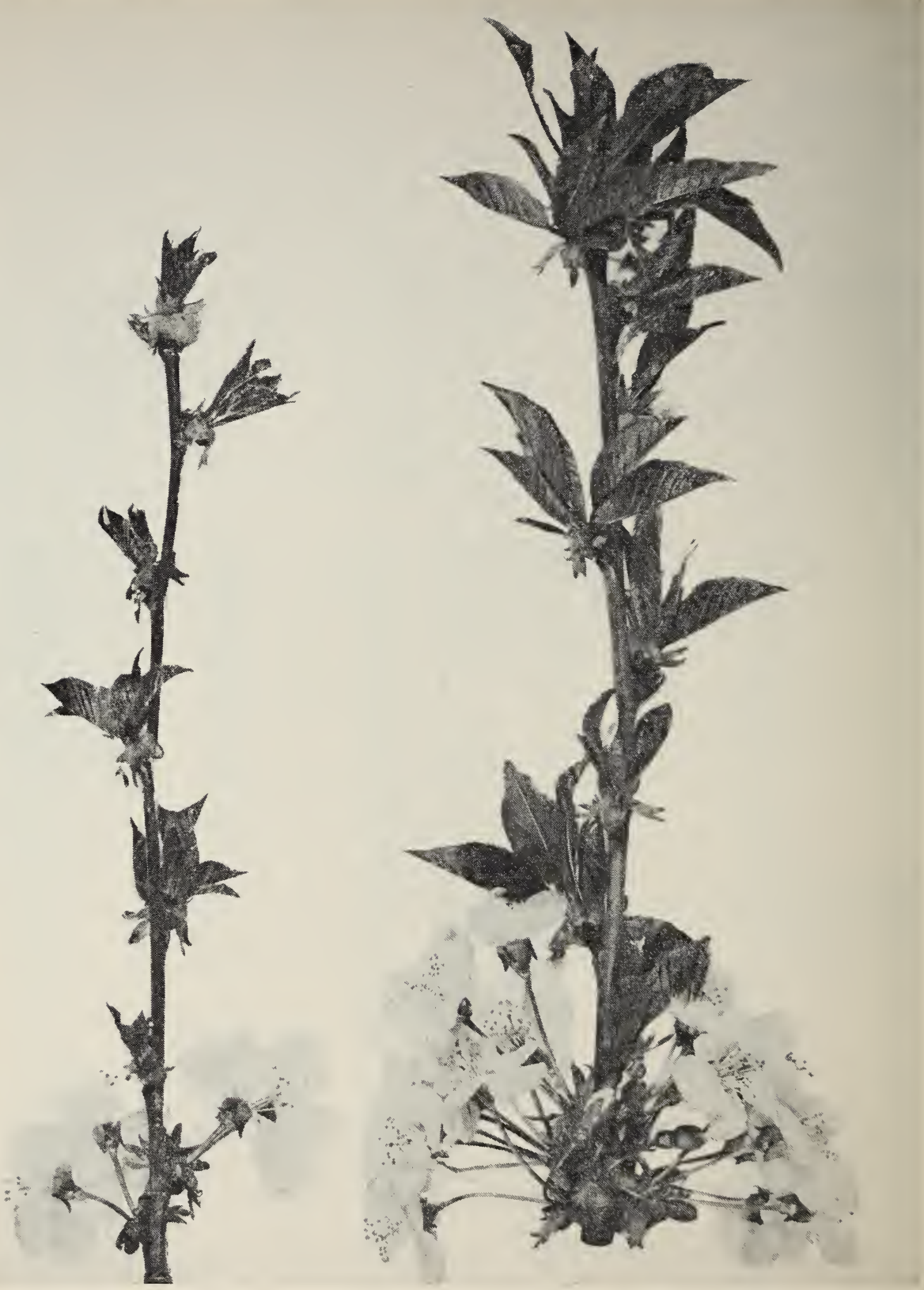

Fig. 3. Sweet-cherry shoots, showing basal position of flower buds. The lower few inches of cherry bud sticks should be discarded. Less vigorous shoots have more flower buds; more vigorous shoots, fewer flower buds. The danger of using flower buds can be greatly reduced by avoiding the shorter, less vigorous type of growth. 
are essentially the same, in size and shape, as the leaf buds.

In all the fruit tree species discussed above, more leaf buds will generally be found on the most vigorous shoots. The danger of using flower buds can be greatly reduced by avoiding the shorter, less vigorous type of growth.

Position of buds in nursery practice. Budding is usually done as near the ground as convenient, but northern California black walnut stock, which is resistant to oak root fungus, is often allowed to extend a foot or more above the surface of the ground. Other kinds of resistant rootstocks are commonly budded 4 , to 5 inches above the soil surface.

Buds are usually inserted on the north side of the seedlings for protection against the sun during healing. In the hot interior valleys of California, however, where summer north winds are common, some propagators prefer to bud on the south side of the tree to prevent drying out of the bud, even though this practice may increase the possibility that the growing bud may be broken off by wind. There is another point in favor of the south side: after the bud has started growth, the short section of seedling trunk on the side below the bud is less subject to sunburn than is the side opposite the bud. Therefore, less injury will occur if this more resistant side is placed on the south. Not only is sunburn in itself serious, but the damage caused by it is often followed by the entrance of flat-headed borers.

$\mathrm{T}$, or shield, budding. This is the method most commonly used for deciduous fruits, except the walnut, pecan, and grape.

A bud with some bark and a thin layer of wood is sliced from the bud stick with a sharp knife and placed beneath the bark of the stock as illustrated in figure 2 . The blade shown has the rounded point commonly found in budding knives. The leaves have been removed from the bud stick by severing the leaf stems, or peti- oles, about $1 / 4$ inch from the buds. Beginners often use the leaf stem as a handle to aid in inserting the bud, but experts generally hold the bud between the knife blade and the thumb. If the bud cannot be easily pushed into place in the $\mathrm{T}$ cut, it may be necessary to pull it into position with the point of the knife. This can be done with very little injury to the bud by inserting the end of the knife a short distance into the shield just below the stub of the petiole. When doing this, hold the blade of the knife perpendicular to the length of the shield.

The details so far discussed refer particularly to late-summer or fall budding. They also apply to spring and June budding, except that no petioles are present on the bud sticks used for spring budding because the sticks are collected in winter when the leaves are not on the trees. In June budding, the wood is usually removed from the buds by some method such as the one described on page 12 .

The $T$ cut in the stock that will receive the bud is generally upright, although sometimes an inverted $T$ has been used. Most budders make the vertical cut of the T first. Then, with a single movement, they make the crosscut and throw open the bark to receive the bud. Some, however, make the vertical slit last. By whatever method the $T$ is cut, the bud is inserted far enough so that its top does not project above the crosscut of the T. The vertical slit should not be longer than necessary to accommodate the bud. If it is too long, the lower part of the shield may not be adequately covered. Although raffia and string have been used to tie the bud, such materials have been practically replaced by budding rubbers, which need not be cut to avoid constricting the stem. These will stretch as the tree grows, and after a few weeks they rot and fall off. Raffia or string, if used, should be cut in 10 days to two weeks. Wrapping should begin at the top of the $T$ and proceed downward so that the bud will not be forced upward. The budding 


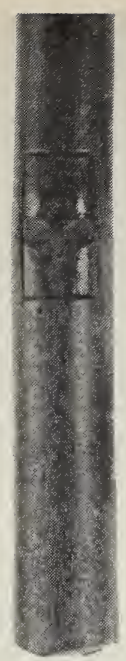

A
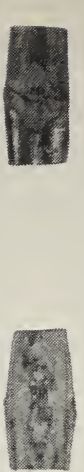

B

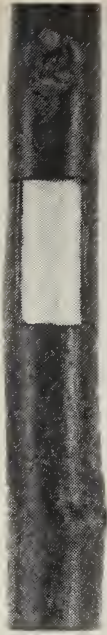

C

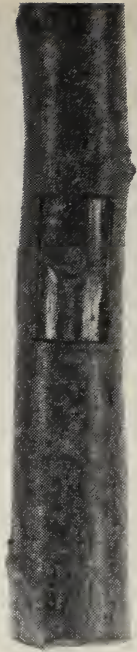

D

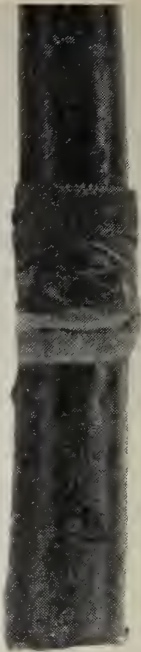

E

Fig. 4. Patch, or flute, budding. A, bud stick with patch cut but not removed; B, patches with buds, removed from bud stick; $C$, patch of bark removed to receive bud; $D$, bud in place; $E$, wrapping completed. Notice that bud itself is not covered.

rubber is held in place by inserting the end back under the last turn. As illustrated in figure 2, the bud itself is not covered by the wrapping material.

With some plants, better results have been reported when the wood has been removed from the buds, but with deciduous fruits this is done only when June budding is practiced and when (in a few instances) T budding is used for walnuts and persimmons.

Patch, or flute, budding. This type of budding is commonly used in propagating thick-barked trees, such as the walnut and pecan. A square or rectangular patch of bark is removed from the seedling and replaced with a similar one that includes the bud desired. This latter patch is slid rather than pulled from the bud stick so that the small core of wood in the bud itself will be retained. Figure 4 illustrates the steps taken in this method. Since a good fit at the top and bottom of the patch is necessary, most tools used have two parallel blades 1 to $13 / 8$ inches apart, for the horizontal cuts. The vertical cuts are made with an ordinary budding knife. The tool in figure 5, center, may easily be made from a small piece of wood, two safety-razor blades, two bolts, and two metal strips, one on the outside of each blade to hold it in place. If considerable work is to be done, a stronger knife (fig. 5, right), consisting of two budding-knife blades rigidly attached to each other, is preferable. This is the type usually used by commercial budders. Some tools have vertical knives in addition (fig. 5, left), but this type of budding knife has not been entirely satisfactory. If the bark of the stock is thicker than that of the budwood, the stock bark must be pared down as shown in figure 6 , so that the patch can be tied firmly in place. The usual wrapping material is waxed cloth or budding tape. String and rubber bands are not recommended because they are less effective in preventing drying out. Waxed clotl, budding tape, or string should usually be cut in two or three weeks. If the stock is making very vigorous growth, however, it may be necessary to cut the wrapping material in about 10 days to prevent constriction. In cutting 

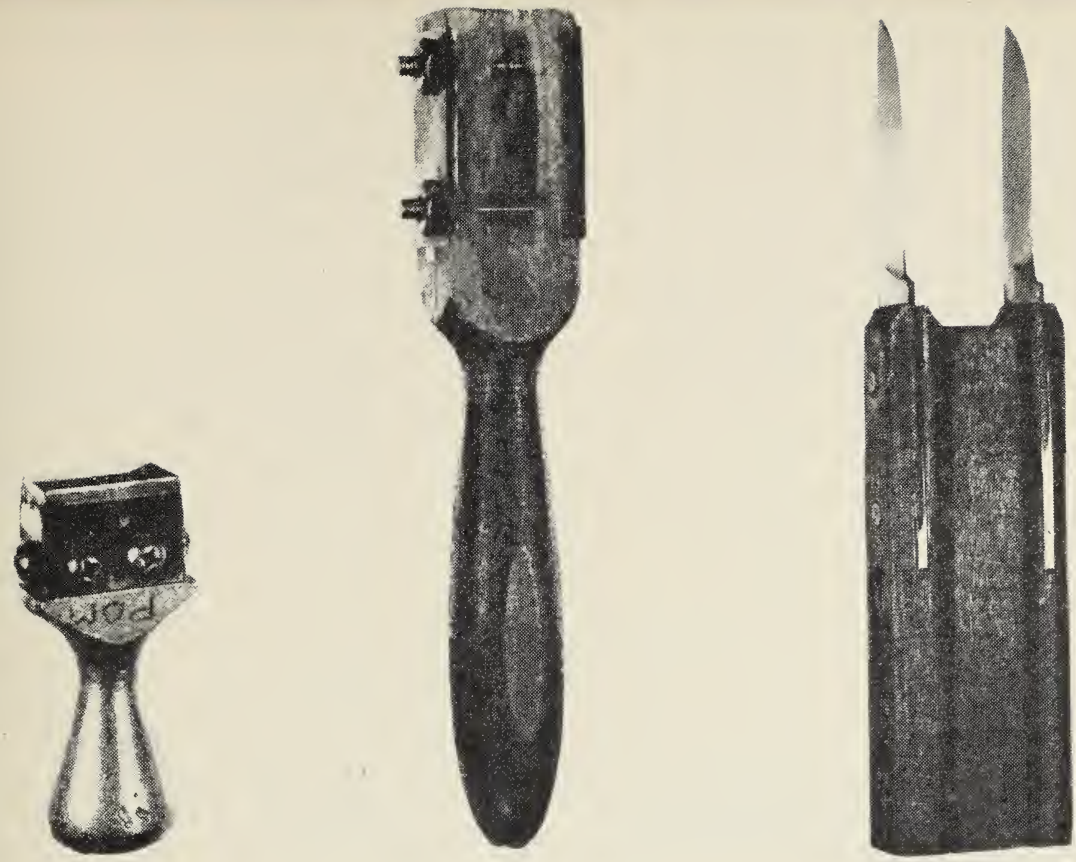

Fig. 5, Patch, or flute budding tools. Left, type with four blades; center, budding tool with two parallel blades, suitable for a limited amount of work; right, two-bladed budding knife of the type usually used by commercial budders.

Fig. 6. Patch, or flute budding stock branches which have bark thicker than that of the budwood. Left, patch removed and stock bark pared down; right, bud in place and ready for wrapping.
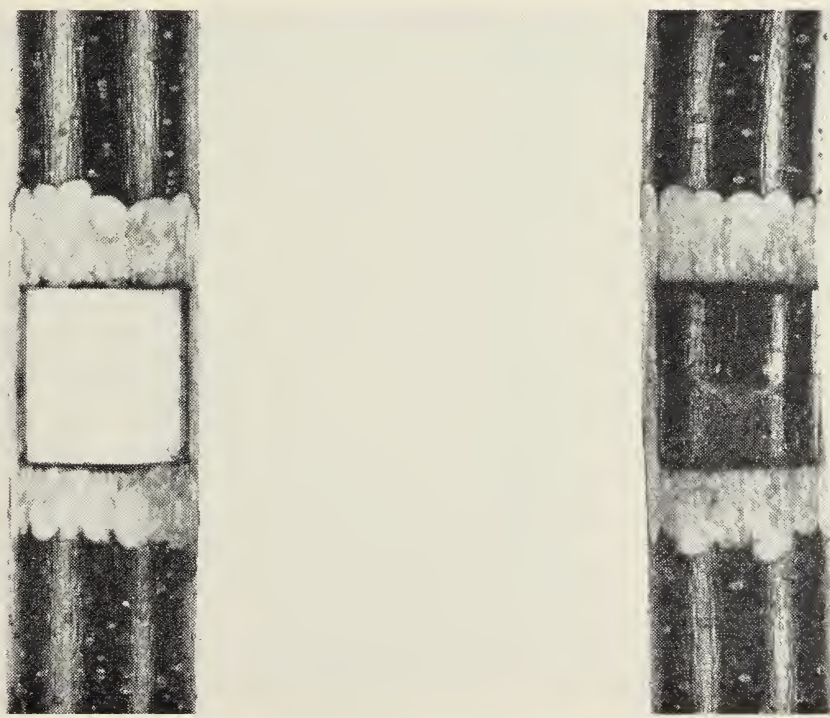
these materials it is best to make the cut on the side opposite the bud.

Since the leaf bases of trees commonly T-budded are not large, they do not interfere with wrapping the bud. Walnut and pecan leaf bases, on the other hand, are rather large and make wrapping difficult. Most propagators cut the leaves off the budwood, except for short stubs, two or three weeks before budding. Leaves on the terminal ends of bud sticks should be left uncut. By the time the bud sticks are removed from the tree, the short stub of the leaf stem, or petiole, has dropped off or may be easily removed.

Many nurserymen whip-graft (see p. 21 ) the seedlings whose buds fail to unite. This work is done in the winter after the budding.

Ring, or annular, budding is the same as patch budding except that a complete ring of bark is removed around the sten. This method is slower and has no particular advantage.

\section{Hinge, $I$, or modified $\mathrm{H}$, budding.}

This method is sometimes used in place of the patch bud when the bark of the stock is considerably thicker than that of the budwood. It eliminates the need for paring down the bark of the stock to hold the patch firmly in place.

The cut in the stock is made in the form of an $I-$ in other words, like an $\mathrm{H}$ on its side. A patch containing a bud (cut as for patch budding) is inserted under the flaps of the I. Wrapping is done as in patch budding. Although this method is reasonably satisfactory, unless care is taken the patch may buckle slightly and not touch the stock under the bud.

Chip budding. In budding small grapevines, more consistent results have been obtained with chip budding (fig. 7) than with other common methods. Rootstock rootings that are resistant to phylloxera or root-knot nematode are planted in the vineyard in the spring and are budded the following August in nonirrigated vineyards, and September in irrigated ones. For good results, the buds must be taken from mature canes in which bark color has changed to brown. In addition, the stock must be growing actively at the time of budding.

Figure 7 shows how a chip is removed from the stock and replaced with a chip of similar size and shape carrying a bud of the desired variety. To facilitate the removal of the bud from the bud stick,
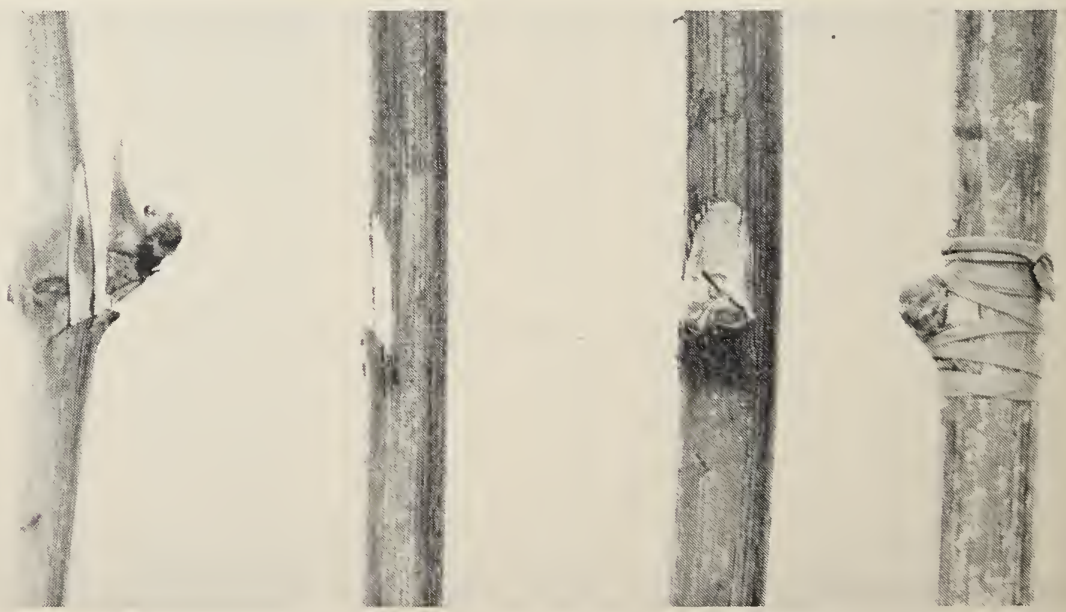

Fig. 7. Steps in chip budding grapes. Left to right: bud removed from bud stick; notch made in stock to receive bud; bud in place; bud tied, ready to be covered with soil. Chip budding is seldom used for deciduous fruits other than grapes. (From Calif. Ext. Cir. 116.) 
the first cut is made at the base of the chip deep into the stick, at an angle of about 45 degrees. The buds are placed just above the ground level and tied with budding-rubber strips. They are covered immediately with about 6 inches of pulverized soil. The rubber must be cut and removed the following spring when the tops of the rootstocks are beginning growth. At that time the top of the vine is cut off about $1 / 2$ inch above the bud union. Chip budding is seldom used for deciduous fruits other than grapes.

Top budding. Budding is done mostly by nurserymen to propagate their plants, but is also used by the fruit grower who wishes to change his trees over to another variety. The only differences between orchard procedure and that followed in nursery work are that the buds are inserted higher in the tree, usually in the branches, and late-summer or fall budding is often done earlier. This earlier budding in the orchard is generally necessary because the trees cannot be kept growing so vigorously in the field as in the nursery, and it is impossible to lift the bark later in the season. Late June, as soon as well-matured budwood is available, or July, is an excellent time to topbud. If budding is done at that time, the top of the branch above the bud is not cut back until about the time growth starts in the spring after the budding. Spring budding in March or April, although sometimes practiced, is usually less satisfactory.

Fairly large limbs may be budded, but with difficulty. If old trees are to be budded, they are usually cut back the winter before in order to force out new branches in which to place the buds. It is usually best to top-bud only young trees and to use some method of grafting for the larger branches in older trees.

\section{GRAFTING}

Grafting differs from budding (which is itself a type of grafting) only in that the scion (a short section of a shoot), instead of a single bud, is placed upon the stock. The different kinds of grafting are classified according to the part of the plant upon which the scion is placed and the actual method of putting the scion on the stock. Based on the position of the graft, there are the following five classes: root grafting; crown grafting; top grafting; bridge grafting; and inarching.

As a rule, closely related plants may be grafted one upon the other. Since there are many exceptions, however, table 1 has been included to show the combinations possible among the common deciduous fruit tree species.

\section{Selection and Storage of Scion Wood}

Scion wood is collected while dormant during the winter. In some cases it may be used immediately, but with certain methods it may be necessary to store the scions in a cool place in moist sphagnum moss, peat moss, or sand. The scions and the moist material may be placed in a box, wrapped in waterproof paper, or enclosed in a polyethylene plastic bag. It is important not to have the moss too wet-it should release only a small amount of water when squeezed. The best place to store the scion wood is in a refrigerator at a temperature a little above freezing. However, a cool cellar or similar location is satisfactory if the storage period is not too long.

Shoots that are soft, with a large pith (central, soft portion of the stem, surrounded by the wood), should be discarded in favor of a more solid type of growth. Often the apical third, or even more, of each shoot must be discarded in order to eliminate undesirable scion wood. The precautions just discussed apply particularly to the English, or Persian, walnut. The danger of using flower buds (see budwood selection, p. 12) is much less in grafting than in budding. Since two or three buds should be present on a scion used in grafting, the likelihood 


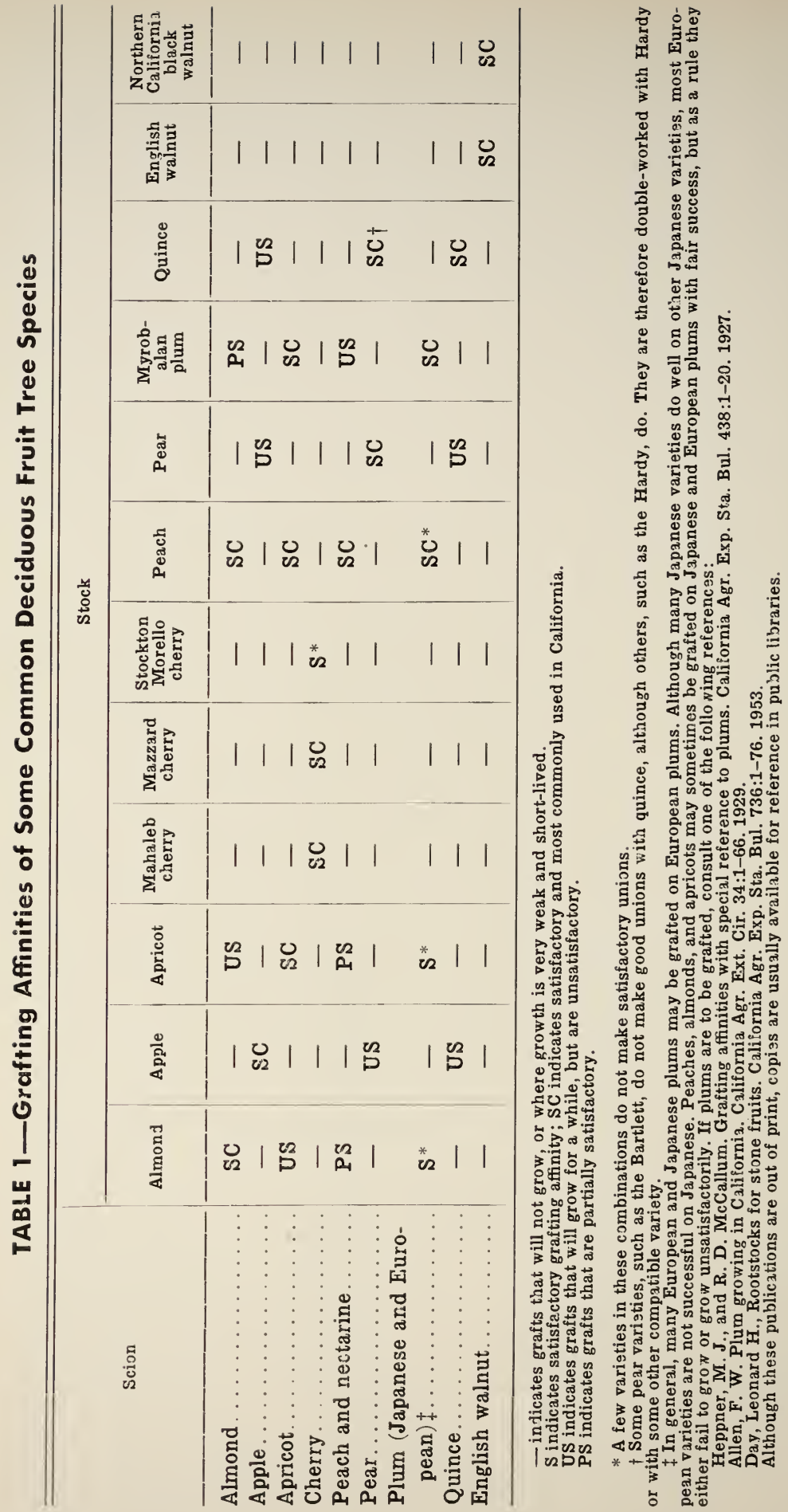


of having at least one leaf bud is greater than in budding, where only one bud (or cluster of buds) is present. Besides. flower buds can be distinguished from leaf buds more easily at grafting time than at budding. Some care should be taken, however, to avoid having too many flower buds on scion wood, especially in the cherry.

Most scion wood consists of shoots that have grown for one season. Usually, such one-year-old branches are of a size suitable for grafting and have enough strong leaf buds. Older wood is sometimes employed if satisfactory buds are present; in the fig, two-year-old scion wood is preferable.

\section{Root Grafting}

This method consists of grafting a scion 3 to 6 inches long on a whole root or a portion of a root. California nurserymen bud instead of root graft, but the method is used by some nurserymen in the Midwest mainly for the propagation of apples. Either piece-root or wholeroot grafts may be used for apples, but whole-root grafts are best for pears. The roots are dug in the fall, and the grafting is done indoors during the winter. Since the work is carried on at a table or bench, the term "bench grafting" is sometimes used. The whip, or tongue, graft is commonly used for root grafting.

Whip, or tongue, grafting. At the base of the scion and the top of the stock, sloping cuts $1 \frac{1}{2}$ to $2 \frac{1}{2}$ inches long are made (fig. 8). The cuts should be adjusted to the size of the branches or roots being grafted; they should be longest on the pieces with the largest diameters. On each of these cut surfaces, starting about one third of the distance from the tip, a reverse cut $1 / 2$ to $7 / 8$ inch deep is made. This second cut should not be with the grain of the wood, but should tend to parallel the first cut. However, if the first cut is long enough, a reasonably satisfactory graft may be made even though the second cut is made with the grain. The two pieces are then fitted together and wrapped. Nurseryman's tape, plastic tape, or a light twine, dipped in melted grafting wax, may be used as wrapping material. Figure 8 (right) shows a whip graft correctly wrapped for top-working, but for root grafting it is usually considered best to wrap the string in a continuous layer in order to produce a smooth union. The various
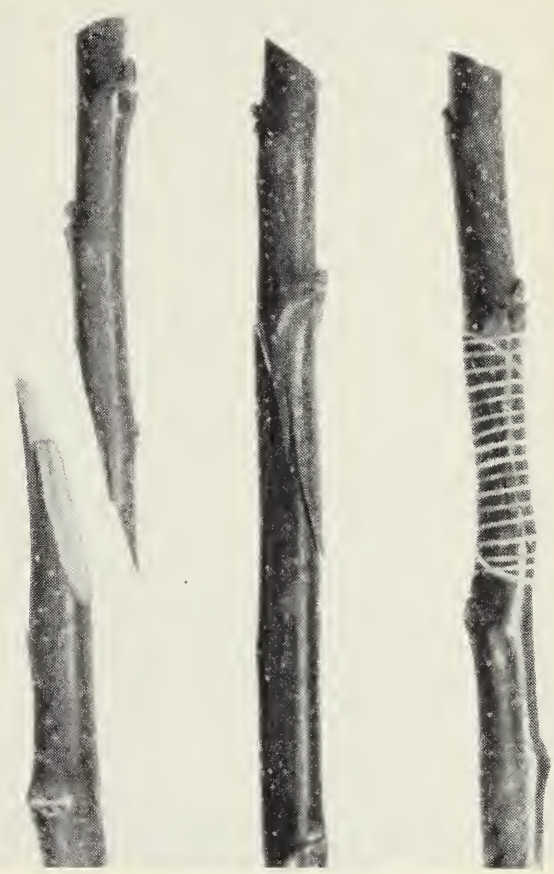

Fig. 8. Whip, or tongue, grafting. Left to right: stock and scion prepared; parts fitted together; graft wrapped with waxed light twine. For top working, where graft union is aboveground, thorough waxing is necessary. If the stock and scion are not exactly the same size, the cambiums cannot be matched on both sides. They are therefore fitted together in such a way that the cambiums of the stock and the scion come together on one side. 
wrapping materials used for whip grafting have their advantages and disadvantages, but nurseryman's tape is considered best under most conditions. At this point, apple-root grafts are ready to plant, but pear-root grafts are usually waxed over except where tape has been used. If the work is done in winter when the nursery is too wet to cultivate, the grafts must be stored until early spring in cool, moist sand, moss, or some similar material. Stored grafts will callus, and unless they are carefully handled, the partial union of the stock and scion may be destroyed. The grafts are usually planted deep enough so that only the upper bud is aboveground.

When the whip graft is used in topworking young trees, all cut surfaces should be covered with wax, except that
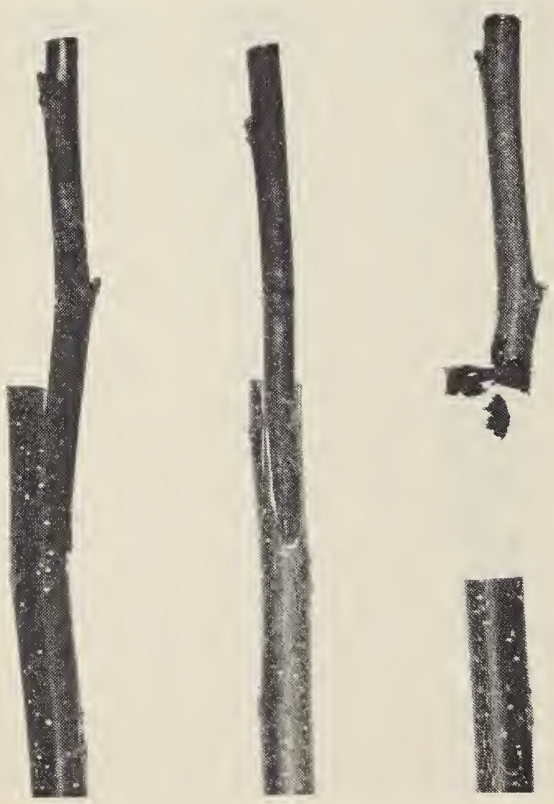

Fig. 9. Modified whip, or tongue grafting for use with stocks that are considerably larger than the scions. Left and center, two views of a prepared graft; right, graft wrapped with nurseryman's tape, and cut surfaces waxed. The cambiums must be matched on one side, but usually only partial matching is possible on the other. with tape the wax is necessary only on the tip of the scion. Tape and the stronger types of string, when used for whip grafting aboveground, must be cut, after the parts have united, to prevent constriction.

Grapes are sometimes whip-grafted to phylloxera-resistant or root-knot nematode-resistant rootstocks; but disbudded cuttings of the rootstock variety, about 12 inches long, are used instead of root pieces.

\section{Crown Grafting}

In this method the graft is made at or near the crown of the plant-that is, just below the surface of the ground. Usually nurserymen in southern California, and sometimes those in the northern section, crown-graft English walnuts instead of using a patch bud. The whip graft (fig. 8), the method used in this type of walnut propagation, may have to be slightly modified if the stock is considerably larger than the scion. The surface of the sloping cut on a large stock will be longer than that of one made at the same angle on a small scion. To eliminate this difficulty, the stock may be cut off squarely (fig. 9) and the sloping cut made just deep enough to expose a surface equal in length to the cut surface of the scion. When nurseryman's tape is used, as in the illustration, wax is applied to the top of the stock and the top of the scion. If the tape shows a tendency to come loose, it may also be desirable to apply a little wax to the free end.

After the graft union is tied and waxed, replace the soil around the base of the tree, and add enough additional fine moist soil to cover the entire scion to a depth of 1 or 2 inches. However, if the trees are to be planted where oak root fungus is present, the graft union should be a foot or more above the soil surface, and the resistant northern California black walnut should be used as a rootstock. It would be difficult to place soil 
over a graft union this high above the ground, but without protection the grafts may be injured by the heat of the sun. A satisfactory procedure to prevent this type of injury is to whitewash the entire above-ground part of the tree, including the scion. (Persimmons are also often crown grafted in much the same manner as walnuts.)

Crown grafting is also practiced in changing from one grape variety to another. In this work either the cleft graft or the notch graft (see top grafting, below) is used. The graft is made 2 to 6 inches below the ground level and is covered with moist soil, but is not waxed.

Late winter or early spring is the usual time to crown graft.

\section{Top Grafting}

This is the usual method of changing from one variety of fruit to another. This and top budding (p. 19) are generally considered together as top-working. In top grafting, scions should be placed in branches of not more than 3 or 4 inches diameter. It is almost impossible to exclude wood-rotting fungi from such large cuts as those shown in figure 10. If good-sized trees must be topworked, usually the grafts are placed high where the branches are reasonably small. This procedure will be more expensive because it requires more grafts. In addition, it leaves more branches that must be kept free of fruiting wood of the original variety. On the other hand, trees grafted high in reasonably small branches will usually bear sooner than trees grafted close to the ground, and the income from this fruit will more than offset the original expense. The tree in figure 11 illustrates a much better procedure than that in figure 10. Sometimes grafting even higher would be feasible. The long scions shown in figures 10 and 11 grew very well, but as a rule, the scions should be somewhat shorter than this because of the danger of their drying out before union takes place.
A limited number of spurs and small branches may be left on the top-worked trees below the grafts or buds to help protect the tree from sunburn and also to manufacture some food for the roots until the grafts are large enough to take over that function. These branches and the water sprouts that appear later must, however, be cut back to keep them reasonably small.

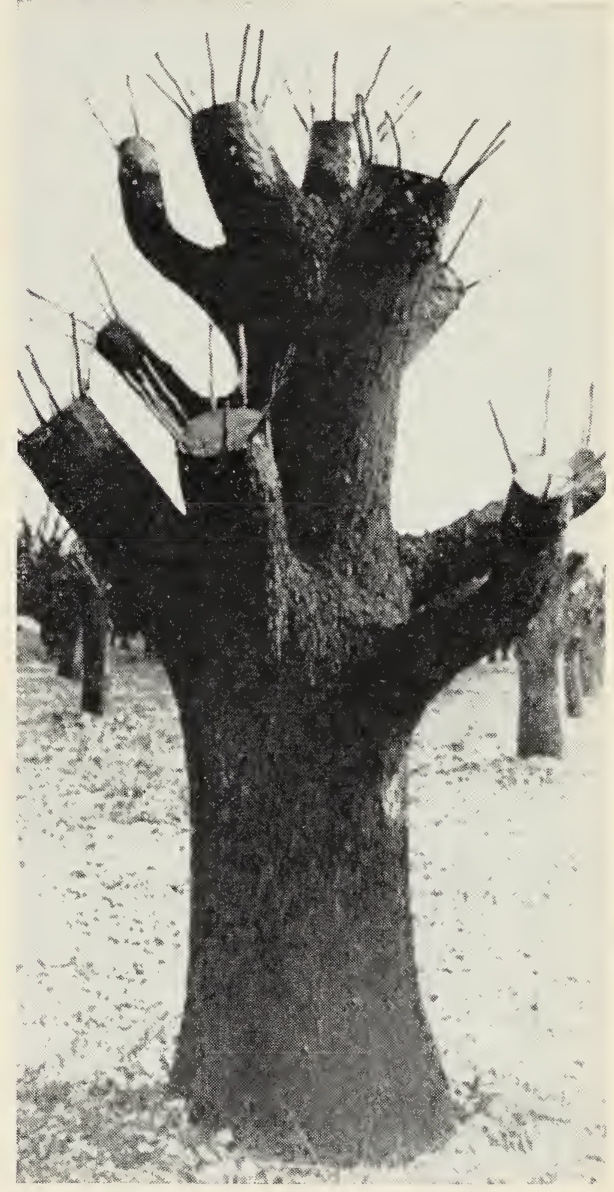

Fig. 10. Glou Morceau pear tree, 55 years old, severely cut back and topworked to Comice. Grafts are in branches that are too large; it will be practically impossible to prevent wood rot in many of the stubs. Compare with figure 11. Although the long scions made good growth, they are about twice as long as necessary. Shorter scions would be less likely to dry out before union takes place. 


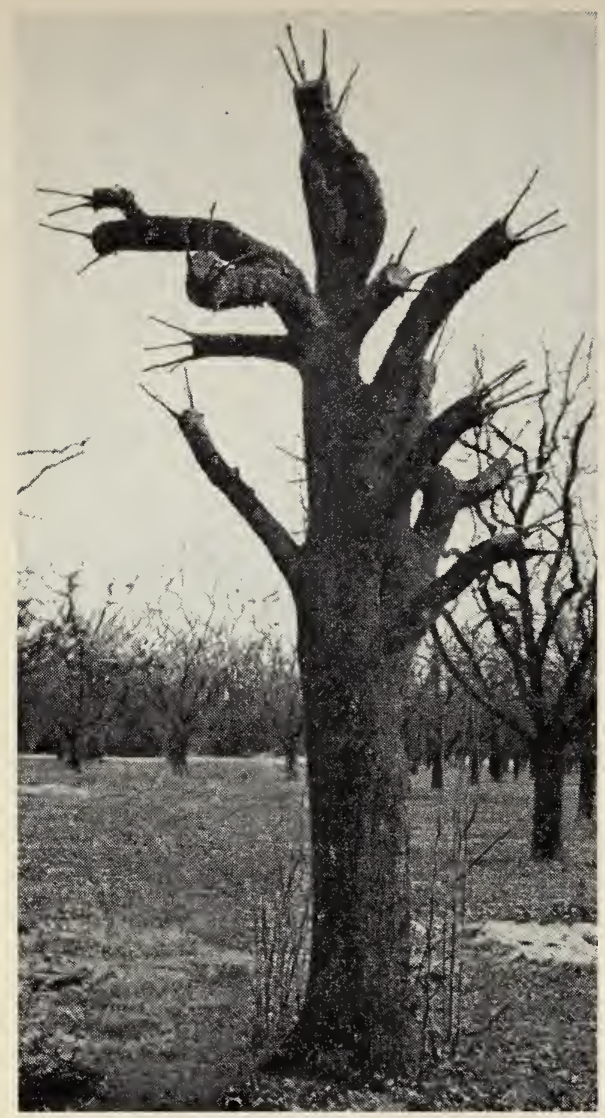

Fig. 11. A somewhat smaller tree than the one in figure 10, but of the same age and variety, in the same orchard. This placing of grafts is more desirable than that shown in figure 10. The grafts are higher in the tree and are made in smaller branches. The long scions grew well, but they are about twice as long as necessary. Shorter scions would be less likely to dry out before union takes place.

Sometimes only a part of the branches is grafted at first, and the remaining ones grafted the next year. This procedure is somewhat more expensive, but no better than cutting off the entire top at the time of grafting, and is not recommended for deciduous fruits in California. In evergreen trees, however, a few branches are often left as nurse limbs until the new tops have become well established, at which time they are completely removed.
The proper season to topgraft trees depends on the method used. For example, bark grafting can be done only in the early spring after the bark of the stock has begun to slip. Cleft, saw-kerf, whip, and side grafting, however, may be done over a rather long period beginning in January. Even earlier grafting has been done, but is usually not advisable because of the danger that the scions may dry out.

Cleft grafting. This method of topworking trees has probably been used more than all others combined. The grafting may be done at any time during the dormant season. It may even be continued after the stock has begun to grow if the scions are kept dormant. If the work is done very early in the winter, however, there is more opportunity for the scions to dry out, especially if the waxing has not been thorough. On the other hand, most propagators believe that more scions will grow if the grafts are completed before the trees have made much growth; consequently, most cleft grafting is done in January, February, and March.

In cleft grafting, after the top of the tree has been sawed off, the stock branches are split down the center (fig. 12). The splitting tool may be either a special one with a concave blade designed to cut the bark first and so prevent peeling, or an old kitchen knife. Whatever type of knife is used, it is driven in $11 / 2$ to 2 inches. It is then removed, and a narrow wedge is driven into the center of the cleft or the split, to hold it open while the scions are inserted. The wedge is often a part of the splitting tool (fig. 12). Some grafters trim the edges of the cleft with a knife, but this procedure is advisable only with difficult species or with unusually rough clefts.

Scions 3 or 4 inches long and containing not over two or three buds (fig. 13) are usually selected from one-year wood of the variety desired. Details concern. ing the type of scion wood to be used may be found on page 19. Scions are cut wedge-shaped, with the outer edge 


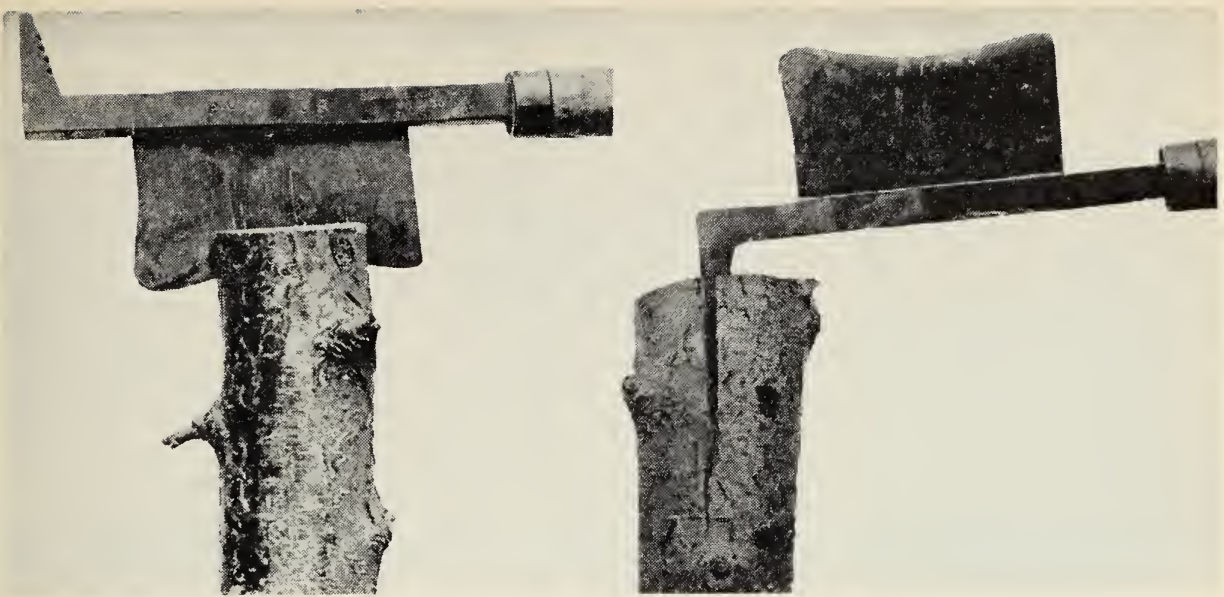

Fig. 12. Cleft grafting. Left, stock split with grafting tool; right, cleft is open, ready for scions. slightly thicker than the inner. This unequal cutting insures contact between the cambium of the stock and the cambium on the outer part of the scion. Figure 14 (center), showing part of the stock cut away, illustrates the proper position of the scions. As this figure indicates, the cambium on the inner side of the scion does not touch the cambium of the stock. If, therefore, the thick side of the scion were accidentally placed to the inside of the stock, it would hold the cleft open slightly and prevent contact of the cambiums. Scions properly placed in thickbarked branches are not flush with the surface of the stock branch, but are set in a distance almost equal to the thickness of the stock bark.

Figure 14. (left) shows wedge removed and the two scions in place. All cut surfaces, including the tops of the scions, are then waxed over. More than two scions may be placed in one stock branch by making more than one cleft. If more than two scions seem desirable, however, either the bark graft or the saw-kerf graft is preferred.

Fig. 13. Cleft grafting: two views of a prepared scion. These are cut wedge-shaped at the lower end (right), with the outer edge slightly thicker than the inner to insure contact of cambiums. The lowest bud should be on outside edge of the scion, just above top of the wedge-shaped cut.
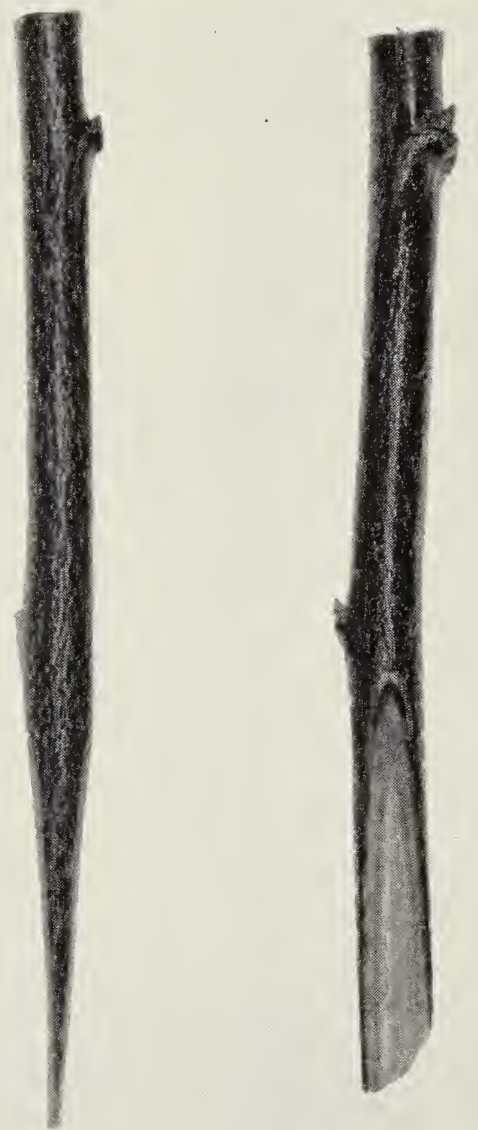

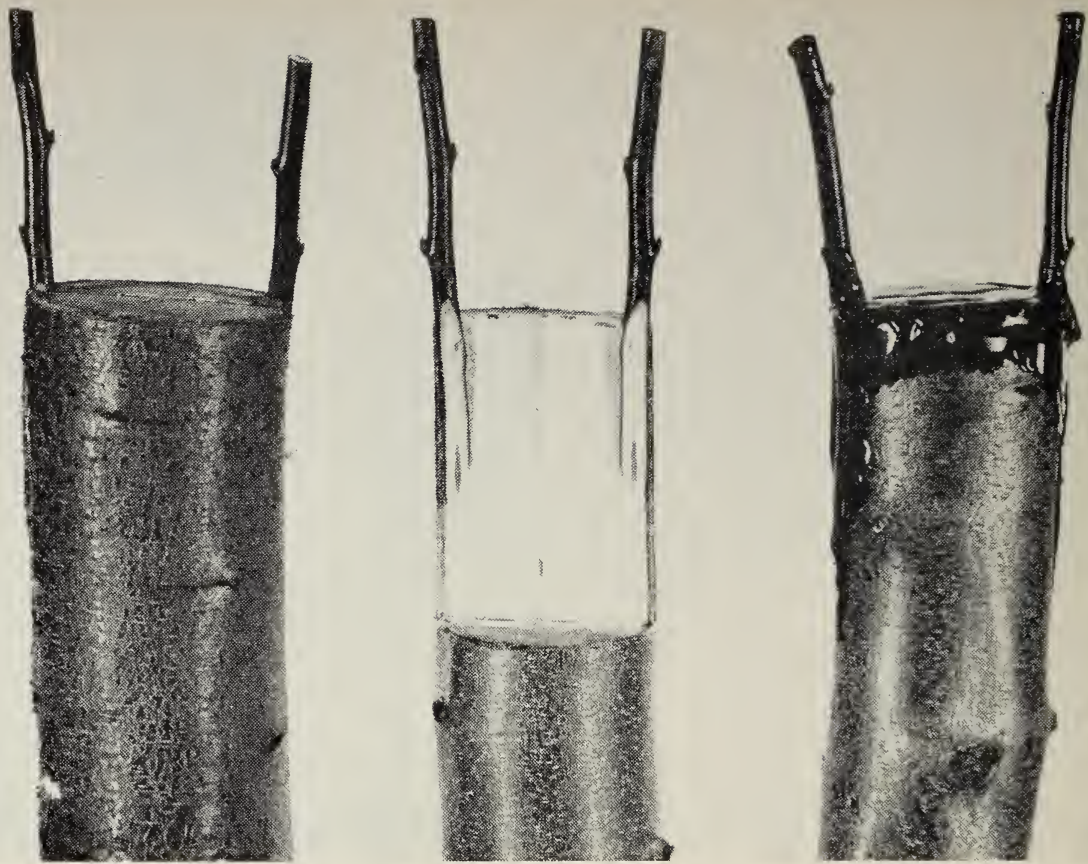

Fig. 14. Cleft grafting. Left, scions in place; center, part of stock removed to show how cambium of stock is brought into contact with cambium of scion. Scions are slanted outward slightly to make sure that cambiums touch in at least one place. Right, completed graft covered with wax.

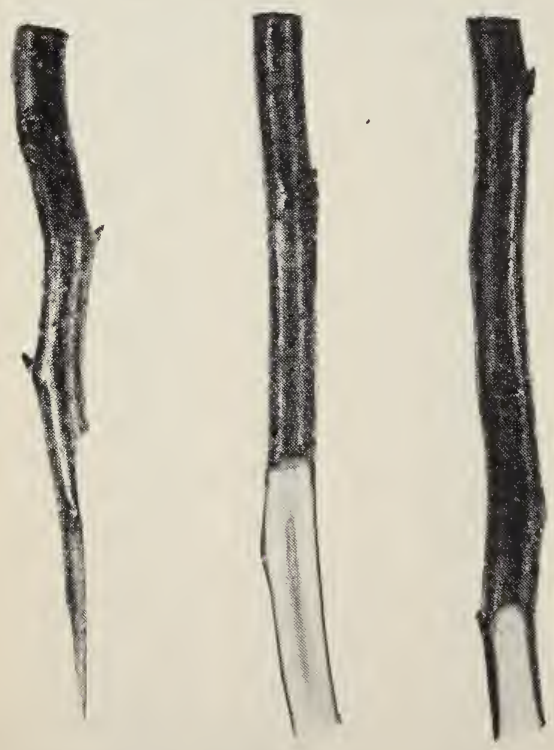

Fig. 15. Bark grafting. Three views of a prepared scion. Left, side view; center, side of scion that rests against the wood of stock; right, opposite side from center.
Cleft grafting is easily performed and may be done successfully over a rather long period. Its disadvantage, however, is that wood-decay organisms may get into the cleft.

Bark grafting. Since the stock is not split in this method, decay organisms cannot enter so easily as in cleft grafting. On the other hand, bark grafting is disadvantageous in that it may be done only in the early spring after the bark has begun to slip. By that time the buds are usually opening on the one-year wood that is to be used for scions. Usually, therefore, the scion wood must be gathered while still dormant and stored in a cool place in moist sphagnum moss, peat moss, or sand. It will keep best in cold storage at temperatures a little above freezing, although a cool cellar or similar location is satisfactory if the storage period is not too long. Additional details may be found on page 19 . 
Storage of scion wood may be unnecessary in some instances where late-leafing varieties are grafted on early-leafing varieties, the scions being taken directly from the tree and used immediately. In addition, in the olive, scion wood may be taken directly from the tree at the time of grafting-March and April in California.

Various modifications of bark grafting have been described, but only three of the best will be considered in detail. If the work is carefully done, all three will give satisfactory results, but some are easier than others.

The bark-grafting method illustrated in figures 15 and 16 will be considered first because it is the type usually described. Although still important, it is gradually being replaced by the other two methods. The scions are usually cut as shown in figure 15, although slight modifications may be made, especially in the size of the shoulder. When nails are used to hold the scions in place, the only function of the shoulder is to reduce the thickness so that the stock bark will not be pushed out too far when the scions are inserted. When waxed cloth, tape, or string is used to hold the scions, the shoulder perhaps helps to keep them in position. Small scions may be made with little or no shoulder, whereas large ones will require a larger shoulder than illustrated. Care should be taken, however, not to make the scions too thin, or they may be broken off after growth begins. Although a perfectly square shoulder may be made with a fine-toothed saw, the results have been no better than when the scions are cut as in figure 15. The slit in the bark of the stock (fig. 16) should be just long enough so that the scion can be pushed in place without splitting the bark. The scion is placed in the center of the slit. As a rule, one nail is then driven through it, and one through the bark of the stock on each side of the scion. Usually an additional nail is put through the lower part of the scion. The proper size of the nails depends on the size of the scion wood, but for most deciduous fruits, except walnut, No. 20 flat-headed wire nails $5 / 8$ or $3 / 4$ inch long are satisfactory. The large walnut scions usually require No. 19 flat-headed wire nails 1 inch long. As soon as possible after the grafting is completed, all cut surfaces, including the tops of the scions, are waxed over.

The use of nails for bark grafting is recommended. The scions can, however, be held in place by waxed cloth, tape, or string wrapped around the stock. These materials should be cut if they show signs of constricting the stock branch.

The second method of bark grafting (fig. 17) has been widely used, and nearly always with good results. The scions are more easily nailed in place, and there is less danger of injuring them than when the first method is used. A single slit is made in the bark of the stock, but the bark is raised on only one side of
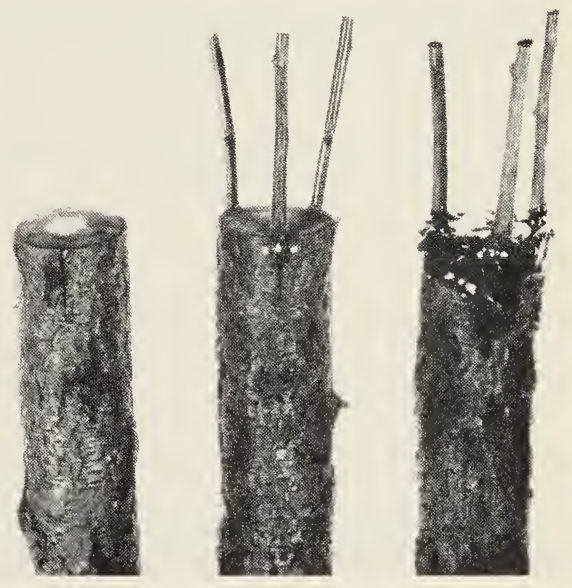

Fig. 16. Bark grafting. Left, slit made in bark of stock; center, scions nailed in place; right, completed graft covered with wax. The use of nails is recommended for bark grafting. If nails are not used, waxed cloth, tape, or string should be wrapped around stock to hold scions in place. 


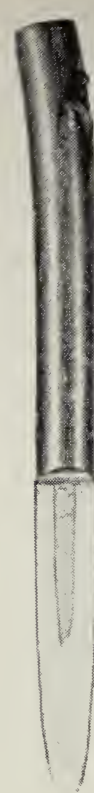

8

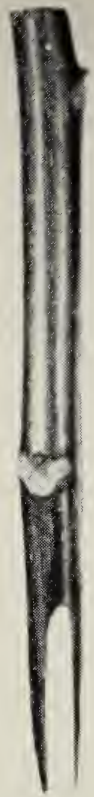

C

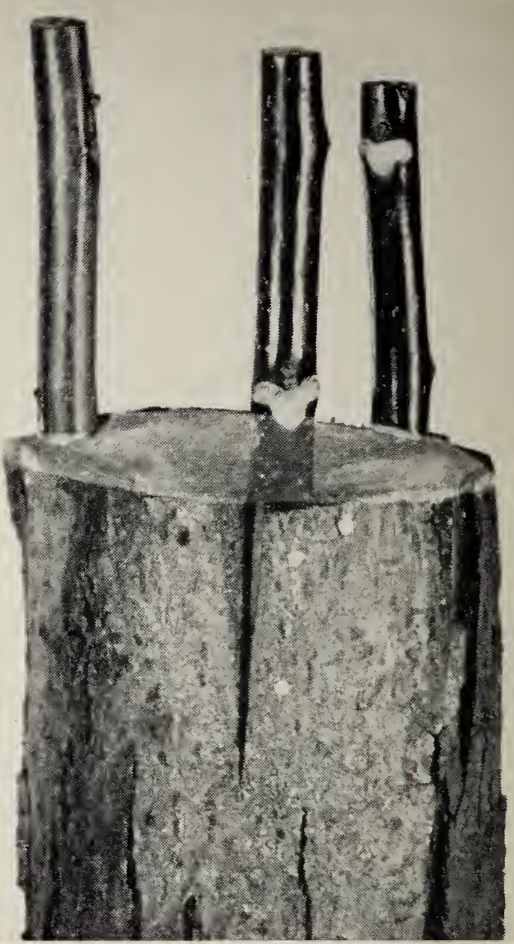

Fig. 17. Modified bark grafting. A, side view of scion; B, side of scion that rests against wood of stock; C, opposite side from B. Right, scions in place. This method differs from ordinary bark grafting (figs. 15 and 16) in that the cut on scion $C$ is not centered, and bark is raised on only one side of the slit. Wax all exposed cut surfaces thoroughly, including tops of the scions.

the slit. A scion cut as in figure 17 is inserted under the raised bark so that one edge will rest against the undisturbed edge of the slit. As in the first method, a shoulder is usually necessary. The scion is held in place by two nails which pass through it and the raised flap of bark. One or two more nails are driven through the bark into the wood of the stock near the scion, to pull the bark tightly into place. Occasionally the bark that is supposed to be left undisturbed is accidentally loosened. It must then be fastened with a nail or two. The scions are cut, as in figure 15, except that the cut on the back of the scion (fig. 17, C) is not centered, but is made near the edge of the scion opposite the side that rests against the undisturbed bark of the stock. This uneven cutting allows the raised flap of bark to fit more smoothly on top of the scion.

Figure 18 illustrates the third method of bark grafting, in which two slits are made in the stock, the width of the scion apart, instead of one. These slits shoull be just long enough so that the scion can be pushed into place without splitting the bark. The scions are usually cut, as shown, without a shoulder. The strip of bark between the two slits is raised, and the upper one third to one half is usually removed. The scion is then inserted under the bark far enough so that only a little of the cut surface extends above the top of the stock. Two nails hold the scion in place, the upper one driven directly into the scion, the lower one driven first through the strip of bark. The scions for this method can be prepared more 


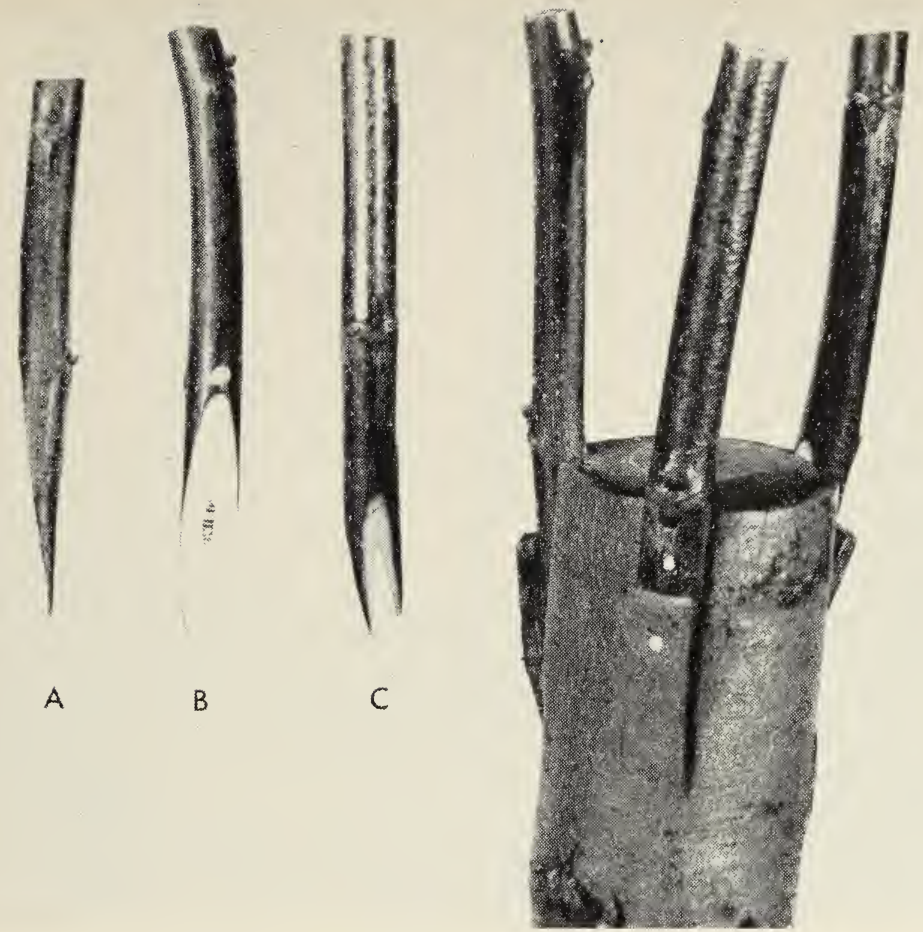

Fig. 18. Modified bark grafting. A, side view of scion; B, side of scion that rests against wood of stock; C, opposite side from B. Right, scions in place. This method differs from ordinary bark grafting (figs. 15 and 16) in that no shoulder is required on the scions, and two slits are made in the stock instead of one. Wax all exposed surfaces thoroughly, including tops of the scions.

rapidly than for the first two methods since there is no shoulder. However, to make the two slits the proper distance apart requires a little more time than to make a single slit. All three methods of bark grafting have given good results, but there is considerable evidence to show that the third method, which does not require a shoulder on the scion, is the most satisfactory for the majority of grafters. In the second method, one edge of the scion rests against the undisturbed bark of the stock, whereas in the third method both edges rest against undisturbed bark. According to some, better contact of the cambiums of the stock and scion should be obtained if the bark on the edge of the scion that rests against the undisturbed bark of the stock is trimmed off just enough to expose the cambium.
A grafting experiment in which English walnut scions were placed on black walnut stock indicated, however, that the extra cut has no effect on the number of scions that grow.

Small scions may sometimes be forced under thick stock bark without a preliminary slit, but it is usually much better to use one of the three methods discussed above.

The lower bud on a scion should be on the outside (figs. 17 and 18), only a short distance above the top of the stock.

Most bark grafting is done on moderate-sized stock branches. Sometimes, however, the method is adapted to small branches by making the inner surface of the scion concave (with a curved chisel), to fit around a small branch. 
Saw-kerf, or notch, grafting. This method has the same advantage as the cleft graft, in that the work can be done over a considerable period. The proper time for grafting is discussed under cleft grafting (p. 24), but most notch grafting is done in January, February, and March. Since the stock is not split, there is less danger from wood-decay organisms than in cleft grafting. In addition, curlygrained stock branches that cannot be split properly for cleft grafting may be notch grafted. Despite these advantages, notch grafting is less common than cleft and bark grafting because it requires considerable skill.

There are two types of notch grafting - deep and shallow. Nails are used to hold the scions in place in the shallow notch but are not necessary for the deep one.

In the first method (fig. 19), the one generally used, a rather deep notch extends approximately to the center of the stock branch. A single cut made with a fine-toothed saw is widened (to fit the scion) with the round knife shown in the photograph. This knife, as used by harness makers, has a blade that is almost the shape of a half circle; but for grafting it should be cut down to the size illustrated. The knife gives best results if one side of the blade is ground flat and the other side beveled as usual. If such a tool is not available, an ordinary grafting knife with a moderately large blade may be used. Most workers find it easier to cut the notch to fit the scion rather than cutting the scion to fit the notch. As in cleft grafting, the scions are wedgeshaped, with the outer edge slightly thicker than the inner. The cambium on this thicker, outer edge of the scion is brought in contact with cambium of the stock. Since it is difficult to line them up perfectly, it is suggested that the scions be slanted outward slightly to make certain that the cambiums touch in at least
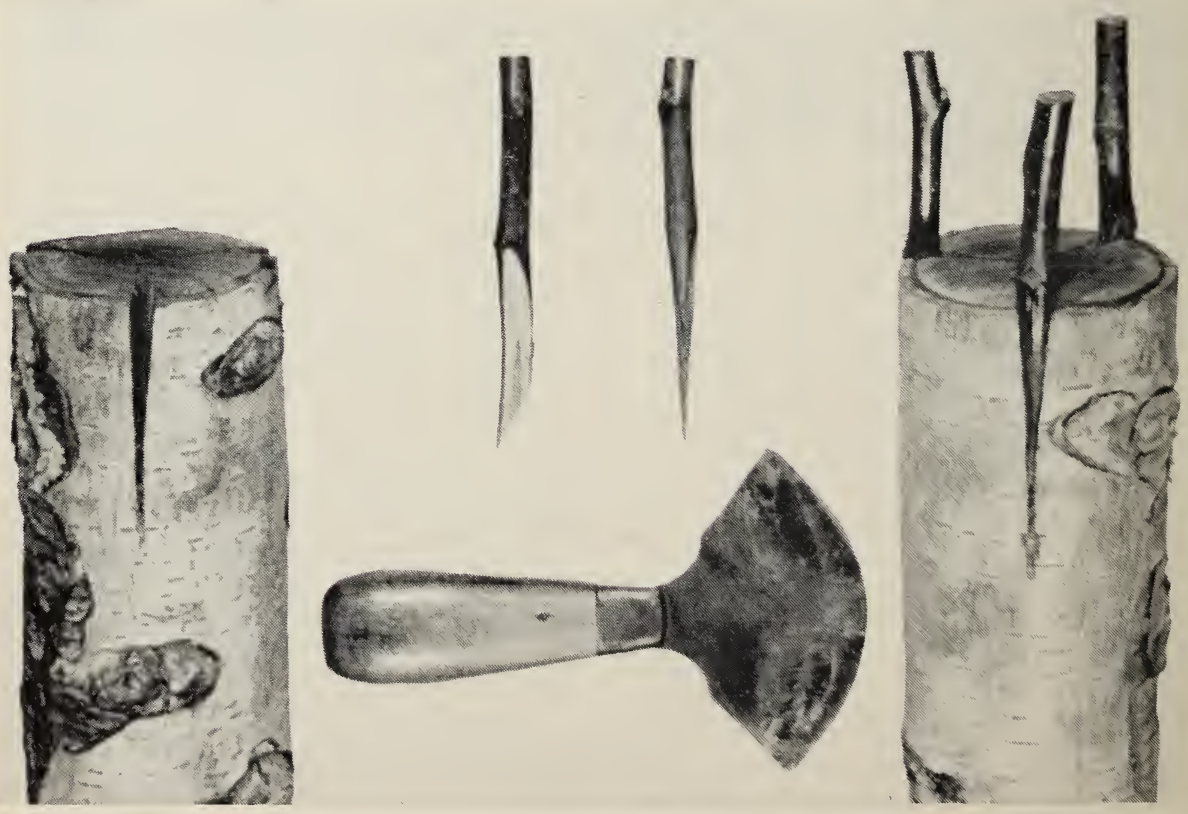

Fig. 19. Saw-kerf, or notch grafting. Left, notches cut; center, two views of a scion; right, scions driven into place. All exposed surfaces, including tops of the scions, should be thoroughly covered with wax. Round knife is used to enlarge notches after single saw cuts have been made. 

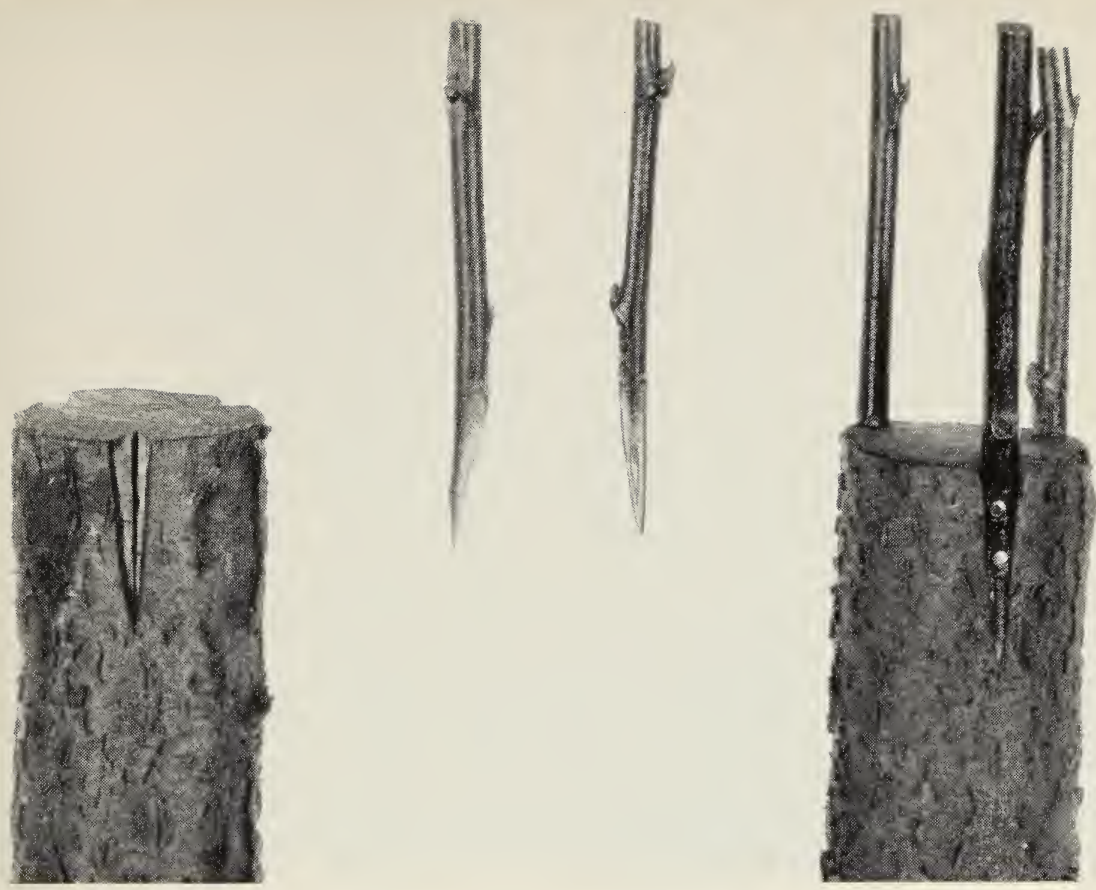

Fig. 20. Saw-kerf, or notch grafting. Left, notch cut; center, two views of a scion; right, scions nailed in place. All exposed surfaces, including tops of the scions, should be thoroughly covered with wax.

one place. The scions must be carefully but firmly driven into position, preferably with a hardwood stick about 1 inch in diameter.

The second method (fig. 20) resembles the first, except that the notch is very shallow. The scions are usually cut as illustrated, with the outer edge considerably thicker than the inner, and are nailed with the flat-head wire nails used in bark grafting. Again, care should be taken to match the cambiums of the stock and the scion.

Scions properly placed in thick-barked branches will not be flush with the surface of the stock branch, but will be set in a distance almost equal to the thickness of the stock bark.

The lower bud on the scion should be on the outside (fig. 19), only a short distance above the top of the stock.

Whip, or tongue, grafting. This method, discussed under root grafting (p. 21), is satisfactory for grafting over young trees in which branches are the same size as the scions, or slightly larger. As in other methods of top grafting, all cut surfaces, including the scion tips, should be waxed. If tape is used instead of string, however, the wax is needed only on the scion tips. The work is usually done in late winter or in early spring.

Side grafting. This method is less commonly used than those already discussed. The graft is usually made as in figure 21 , but there are many possible modifications, including some that require special tools. The method is most useful for branches about 1 inch in diameter-that is, too large for satisfactory whip grafting but somewhat small for cleft, bark, or saw-kerf grafting.

The oblique cut in the stock is made with a chisel or a heavy knife. The scion is usually wedge-shaped, as in the cleft 
graft. For best contact of the cambiums, the scion may be inserted as in figure 21 , but the cambiums will touch in at least one place in any event. The stock branch is bent to open the cut, and the scion is inserted. Although the tension of the wood will usually hold the scion in place, small nails or string can be used. The stock branch is generally cut off just above the point of insertion of the scion, and all cut surfaces are waxed.

Some workers allow side grafts to grow a year before removing the entire tops of the grafted branches, in order to save part of a year's crop while the grafts are growing, but this procedure is rarely successful.

Sometimes a side graft may be placed on the side of a rather large branch if additional branches are desired in that position. The method of making the graft on large branches varies with the individual worker. Usually, however, a diagonal slit is cut, with a chisel or a saw, through the bark of the stock and a short way
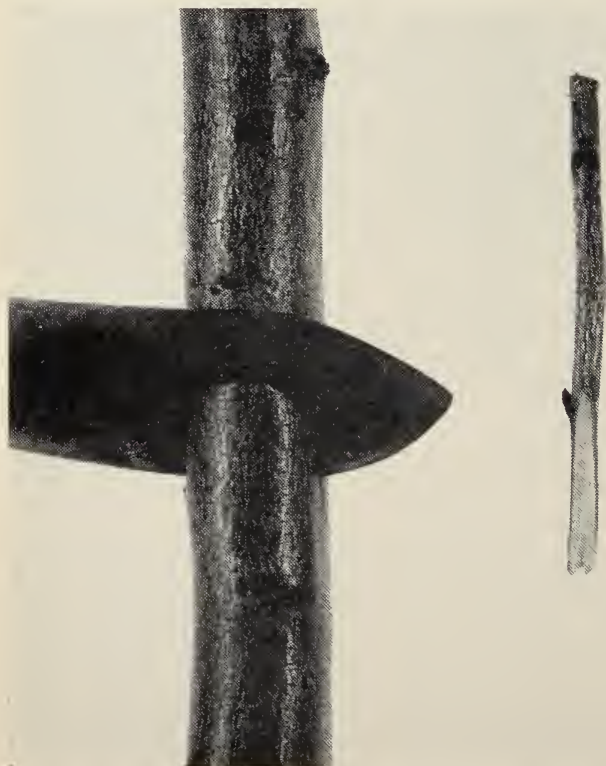

into the wood. The scion is driven into place so that the cambiums touch.

\section{Subsequent Treatment of Top-worked Trees}

The care of the tree during the first few years after grafting is as important as the operation itself-a fact not commonly realized until breakage begins to occur because of heart rot and weak crotches.

As soon as the grafting is completed, the tree, including the scions and the waxed areas, should be thoroughly white. washed to help prevent sunburn. However, if a water emulsion of asphalt is used instead of a hot wax, it must be allowed to dry before the whitewash is applied. Paper bags with holes cut in the corners to provide ventilation are sometimes placed over the grafts to protect the scions from the sun, but experiments have demonstrated that whitewash is more effective. From this time until the trees start growing, an occasional inspec.

Fig. 21. Side grafting is most useful for branches about 1 inch in diameter. Left, oblique cut in the stock; center, two views of a scion; right, scion in place. Nails may be used to hold the scion if necessary. If top of the grafted branch is to be removed at once (the usual procedure), a cut should be made just above the point of insertion of the scion, as indicated by broken line. All exposed cut surfaces should be waxed. 
tion and possibly some rewaxing are all that need be done. When growth begins, however, cracks will always appear in the wax and allow decay organisms to enter the wood. Then the grafts must be watched carefully and rewaxed when necessary. In those cases where considerable rewaxing is required, it is desirable to cover the newly waxed areas with whitewash.

If water sprouts appearing below the grafts are allowed to grow without restriction, they will usually choke out the grafts. This trouble may be prevented by removing all water sprouts. A better procedure, however, is to thin them out and cut the remaining ones back severely to keep them reasonably small. They will then help protect the tree from sunburn and also manufacture some food for the roots until the grafts are large enough to take over that function. The water sprouts must not be permitted to become too large.

If more than one scion grows on a branch, probably not more than one should be retained permanently, otherwise a weak crotch is likely to be formed. The branches to be saved should be pruned as lightly as possible to encourage rapid growth, and those that will later be removed should be pruned heavily to keep them from becoming too large (fig. 22). The suppressed branches help to heal over the stub, and are removed when that purpose is accomplished.

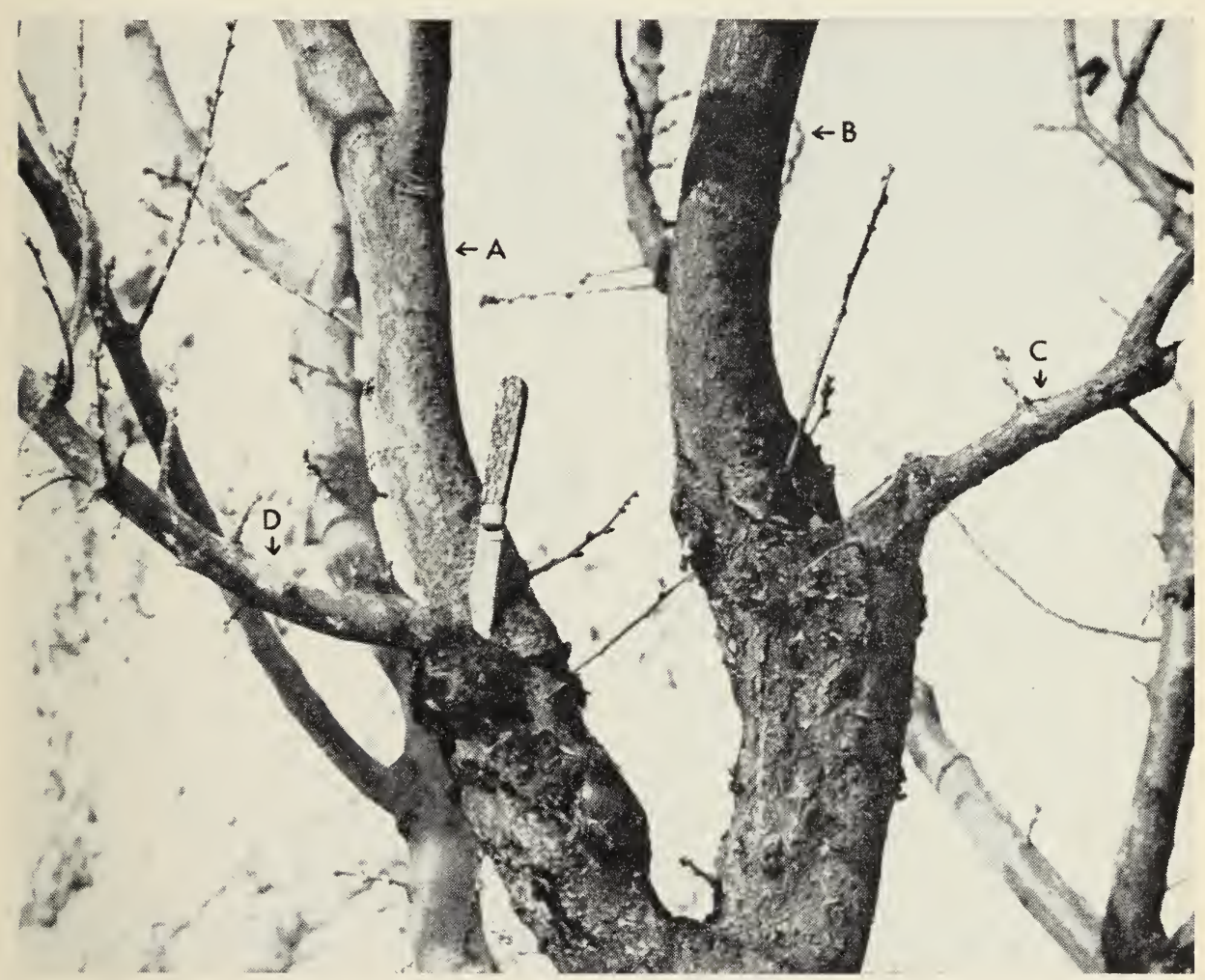

Fig. 22. Apricot grafts after two seasons' growth. $A$ and $B$ show grafts that are to be saved. These were pruned lightly during the first dormant pruning and have grown very well. $C$ and D show grafts that were saved temporarily to help heal the stub. These were pruned heavily during the first dormant pruning and have made little growth. All grafts were approximately the same size at the end of the first season's growth. 
If only one scion grows, the square shoulder on the opposite side of the branch will die and probably decay before healing over. More rapid healing will take place if a sloping cut is made downward and away from the side where the scion is growing. The cut surface should be thoroughly waxed.

Often young grafts, especially of walnuts, need to be supported with laths or strips of wood for a few years (fig. 23). If the grafts have made only a small or a moderate amount of growth, they may not require support or any other special treatment. If grafts of stone fruits, such as apricots and plums, grow extremely fast, and the use of supports is considered uneconomical, then the best procedure is

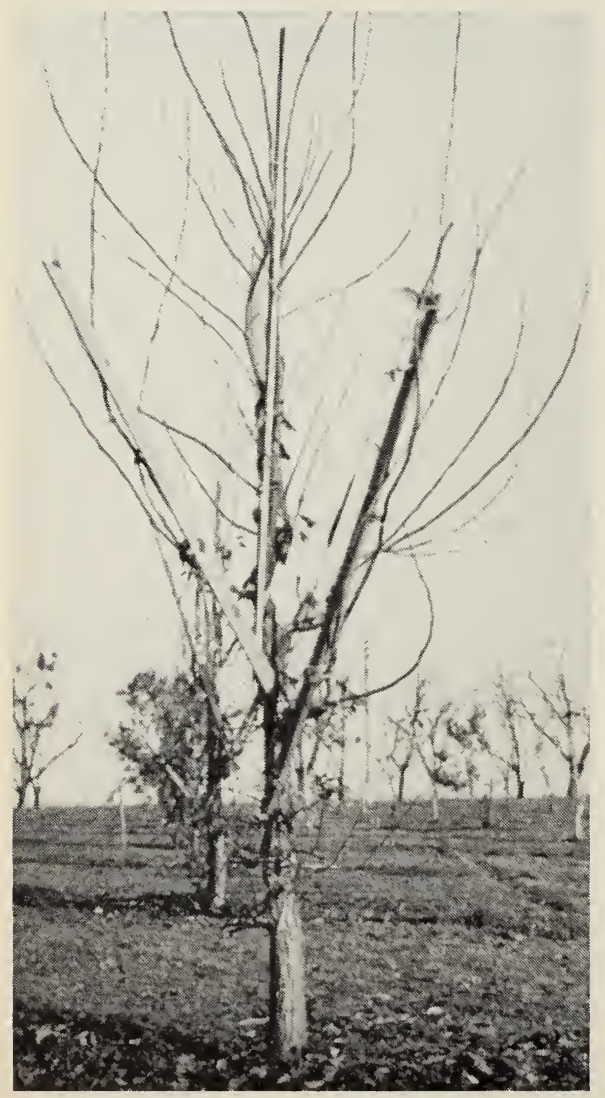

Fig. 23. Often young grafts need to be supported with laths or strips of wood for a few years. to pinch off a few inches at the ends of the grafts after they have grown about 18 inches. Later pinching back may also be desirable. This treatment slows down the growth enough to allow the succulent shoots to mature somewhat and thus keeps them from breaking or bending. Some of the shoots may be thinned out to reduce wind resistance.

\section{Bridge Grafting}

Each year many trees are partly or completely girdled by rodents, pear blight, or mechanical injury. Often the tree can be saved by bridging over the injured area. In the early spring, as soon as the bark of the injured tree will slip, scions (fig. 24) are inserted into the live tissue (fig. 25) above and below the wound. It is best to gather the scions while they are still dormant, and store them in moist sphagnum moss, peat moss, or similar material in a cool place to keep them dormant until they are needed. In some cases, however, it is possible to gather scion wood at the time of grafting. If this is done, any lateral branches that have started to grow on the scion wood are removed, and the resulting cuts are waxed over. In one experiment, sweet cherry was successfully bridge grafted by this method in early May. Although the use of many scions is desirable, one every 2 or 3 inches is usually satisfactory. The scions are cut wedge-shaped at both ends, but the cut on one side is only about half as long as that on the opposite side. The wedgeshaped ends are then inserted under the bark so that the longest cut surface is next to the wood of the tree. Two slits are made in the bark of the tree to receive the scion, in the manner described for one of the methods of bark grafting (fig. 18). The scions are then nailed in place. If they are made slightly longer than the space to be bridged, they will bow out slightly, and the flat cut surfaces will rest squarely against the wood of the stock. 


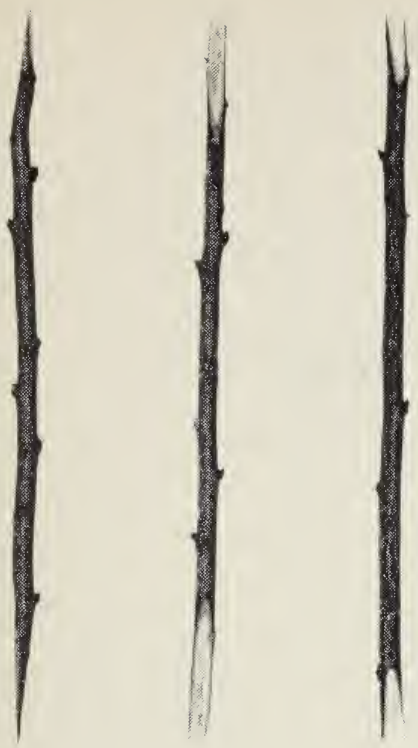

Fig. 24. Bridge grafting: three views of a prepared scion. Left, side view; center, side of scion that rests against wood of stock; right, opposite side from center.

The part of the graft where the scions are inserted under the bark must be waxed over. Preferably, the exposed wood in the girdled area should be covered with wax or some of the materials used on pruning cuts, but this is often not done. Remove all buds that start to grow on the scions.

Figure 26 shows how a tree girdled by rabbits was saved by bridge grafting. If suckers or water sprouts appear below the injury, these may be grafted in above, with the same results.

\section{Inarching}

Inarching is a method whereby two plants are made to unite while growing on their own roots. With fruit trees, a young seedling is generally planted beside an older tree and grafted into the trunk (figs. 27 and 28). The usual pro-

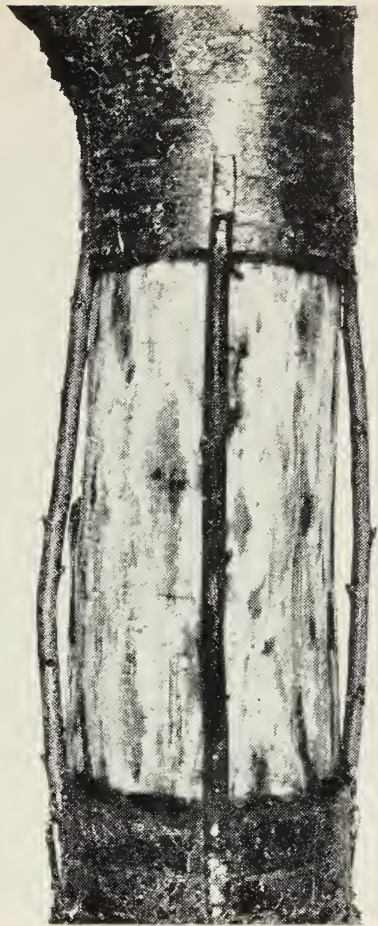

Fig. 25. Bridge graft scions in place. The part of the graft where the scions are inserted under the bark must be thoroughly waxed over for protection.

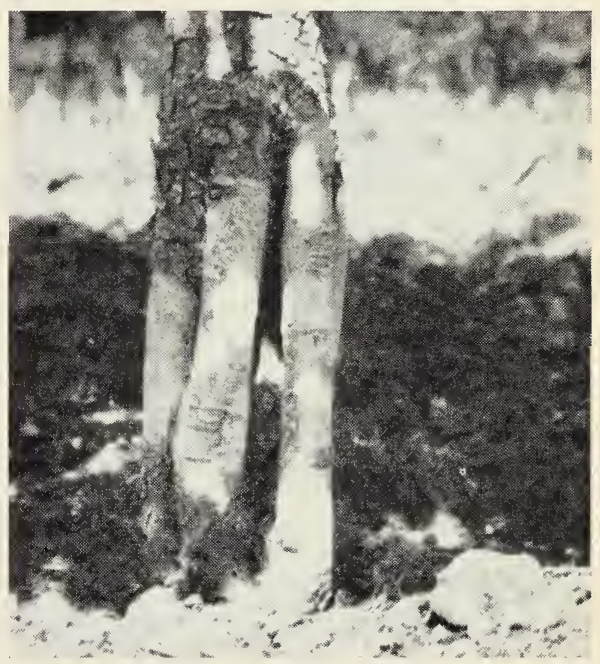

Fig. 26. Bridge grafting. This tree, injured by rabbits, was saved by bridge grafting. If suckers or water sprouts appear below the injury, these may be grafted in above, with the same good results. 


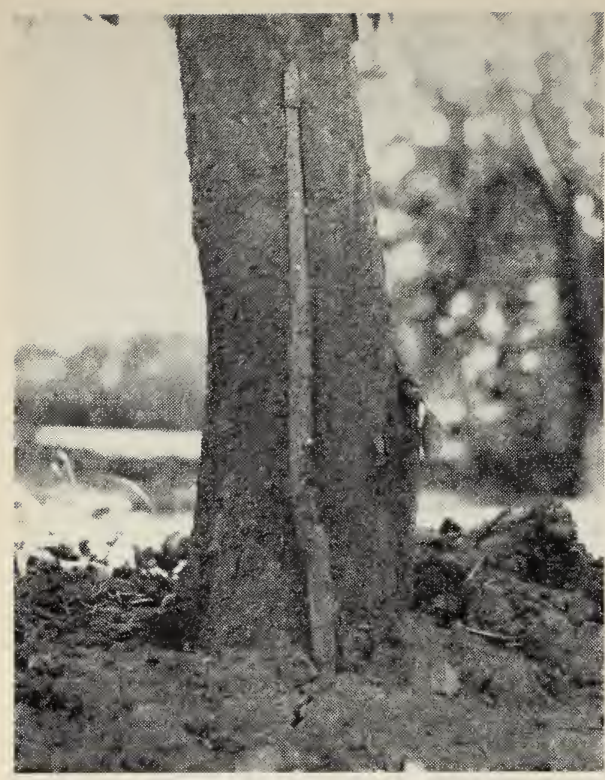

Fig. 27. Inarching. A seedling tree has been grafted into the trunk of an older tree. All exposed cut surfaces should be waxed.

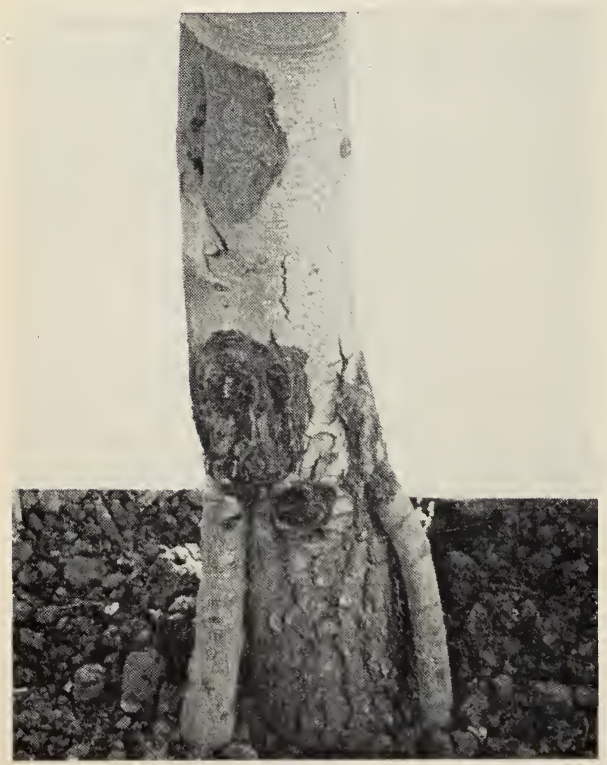

Fig. 28. Two seasons' growth following inarching. A young fruit tree seedling is generally planted beside an older tree and grafted into the trunk. cedure is to remove, from the trunk of the larger tree, a strip of bark as wide as the seedling trunk and 4 to 6 inches long, and then to lay the seedling trunk in this slit. The vertical cuts are best made with the round knife shown in figure 19. About half of the part of the seedling trunk that lies next to the wood of the tree should be cut away to insure contact of the cambiums. Usually, in order to make the union more certain, the end of the seedling is cut wedgeshaped, as in bark grafting, and shoved under the bark at the top of the slit (fig. 27). The seedling should then be nailed in place, and the cut surface waxed. Some of the shoots that appear on the inarches should probably be saved for the first growing season, but they must be suppressed by pinching back their tips. After the union is well established, all shoots should be removed. The work described is best done in the early spring as soon as the bark of the injured trees will slip.

In inarching walnuts it is best to allow a portion of the seedling (usually a section containing three or four buds) to extend above the graft. Leaves are allowed to develop on this section during the first growing season. The part above the graft is then removed at the end of the first growing season if the union appears to be well established.

Inarching may be successfully used to save trees in which roots have been damaged by pear blight or gophers. If the tree has simply been girdled and the roots are alive below, bridge grafting is the best method.

When it was discovered that the Japanese root produced black-end trouble, many pear orchards on that rootstock were inarched with French pear seedlings. The object was to eliminate the Japanese root when the inarches became large enough. A survey has shown, however, that many of those grafts did not grow, or remained too small. There is also the danger that decay organisms 
may enter when the Japanese root is finally severed. Inarching, therefore, is not recommended for this purpose.

\section{GRADES OF NURSERY TREES}

The Agricultural Code of California specifies that deciduous fruit and nut trees shall be graded by size. The type of measurement depends on the kind of tree involved. Sometimes the height is measured, sometimes the diameter of the trunk 2 inches above the center of the bud union.

All nut trees except almonds must be graded by height. The grades in terms of feet are as follows: 1 to $2 ; 2$ to 3 ; 3 to $4 ; 4$ to $6 ; 6$ to 8 ; and 8 to 10 . No tree shall be less than 1 foot high.

Deciduous fruit and almond trees must be graded by diameter of the trunk. It is also permissible to state the approximate height, and this is usually given. The grades are listed below.

$\begin{array}{lc}\begin{array}{l}\text { Diameter } \\ \text { inches }\end{array} & \begin{array}{c}\text { Height } \\ \text { feet }\end{array} \\ 1 / 4 \text { to } 3 / 8 & 2 \text { to } 3 \\ 3 / 8 \text { to } 1 / 2 & 3 \text { to } 4 \\ 1 / 2 \text { to } 11 / 16 & 4 \text { to } 6 \\ 11 / 16 \text { and up } & 6 \text { to } 8\end{array}$

It is required that these trees shall not be less than $1 / 4$ inch in diameter or less than 8 inches in height, except that Junebudded trees may be as small as $3 / 16$ inch in diameter. June-budded trees under $3 / 8$ inch in diameter may be graded into the additional three following sizes: $3 / 16$ to $1 / 4 ; 1 / 4$ to $5 / 16$; and $5 / 16$ to $3 / 8$.

Grades for other kinds of trees and vines have also been set up by law. Consult the Agricultural Code of California for these and for further details concerning the grades discussed above.

\section{WAXES AND OTHER GRAFTING MATERIALS}

Most grafting waxes are a mixture of resin, beeswax, lampblack, and either linseed oil or tallow. Some combinations of these are soft enough to be applied with the hands, but in California the general practice is to make the wax fairly hard, melt it over a fire, and apply it with a brush.

A satisfactory wax consists of 5 pounds of resin, $3 / 4$ pound of beeswax, $1 / 2$ pint of raw linseed oil, 1 ounce of lampblack, and $1 / 2$ ounces of flake fish glue. Melt the resin first, then add and melt the beeswax. Take from the flame, and stir in the linseed oil and lampblack. Heat the glue in a double boiler with just enough water to dissolve it. The glue should then be added slowly, while stirring, to the wax which has been allowed to cool somewhat, but is still in a liquid form. If the glue is added rapidly while the wax is still very warm, the whole mass will boil over.

Most grafting waxes contain lampblack or, occasionally, a red pigment. Since these materials give the wax a color different from that of the trees, it is easy to determine when the grafts are covered.

If only a small amount of wax is required, it is more convenient to buy a prepared product. In recent years water emulsions of asphalt have appeared under various trade names. They are easily applied cold and are, as a rule, satisfactory. However, they may be washed off if rain occurs before they have thoroughly dried. Similar materials containing mineral solvents should not be used for grafting.

Waxed cloth and string may be prepared by dipping muslin or other cloth and light twine in hot grafting wax. The lampblack is usually omitted when the wax is used for this purpose. It is also a common practice to prepare waxed cloth by dipping the material in melted beeswax.

Nurseryman's tape or budding tape usually comes in rolls $1 / 2$ inch wide. It should be used when available, but cloth masking tape which is manufactured for use by painters also has given very good results. 


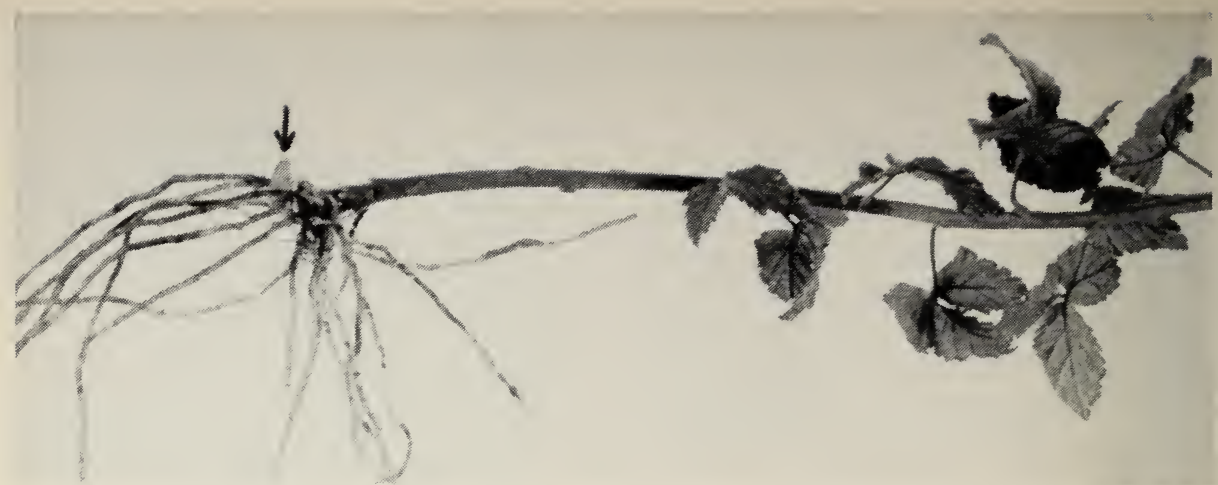

Fig. 29. Tip layer of blackberry. The arrow points to the tip of a layered cane which will develop into the top of the new plant. Ends of canes are covered with earth during latter part of the summer.

\section{LAYERING}

Layering is the operation of rooting stems that are still attached to the parent plant.

Simple layering. This method consists of laying down a branch and coving part of its length with soil, leaving the tip uncovered. Roots often form more readily if the buried portion of the branch is girdled or notched. In the dormant season the rooted shoot may be severed from the parent plant. This method may be used in propagating small numbers of plants of various shrubs and of grapes, but not in producing most deciduous fruits commercially. However, it is at present the most common way of propagating filberts.

Tip layering. The common way to propagate trailing blackberries, dewberries, and black raspberries is by tip layering. The ends of the canes are covered with a shovelful of earth during the latter part of the summer. The covered portion sends down roots and forms a plant that can be set out the following spring (fig. 29). About 6 inches of the original layered cane are left attached to serve as a handle. This old stem will also act as a marker or guide in cultivating, until the new shoots appear above ground.

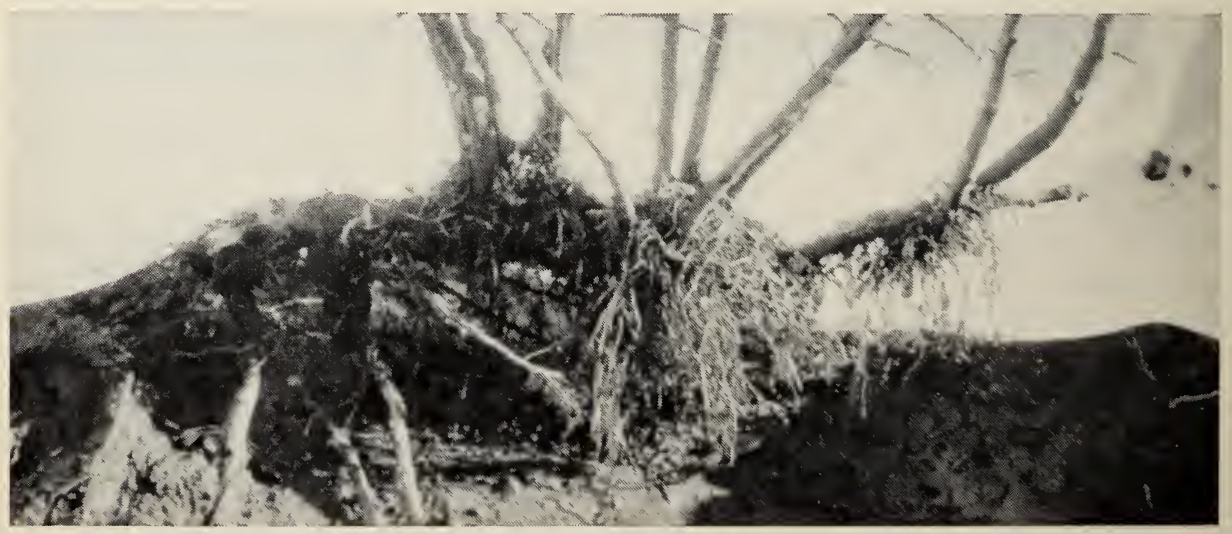

Fig. 30. Trench layering. Soil has been removed to show plant in position. These rooted shoots were produced in one season. The whole top of plant is bent over and pegged down in a trench 2 or 3 inches deep. 
Mound, or stool, layering. Before growth starts in the spring, the mother plants are cut back close to the ground. Soil is mounded around the bases of the new shoots as they grow during the spring, but the tips are not covered. The mound is built up to a height of 8 to 12 inches. Roots arise from the bases of the new shoots, growing into the mound of soil. If the mounds are kept moist through the summer the shoots are usually well-rooted by winter when the soil is removed and the rooted shoots are cut off. These are often lined out in the nursery row the second spring, and grown an additional year to produce stronger plants. Mound layering is used in the commercial production of gooseberries, currants, quinces, and certain vegetatively-propagated plum and apple rootstocks.

Trench layering. This method consists of bending over the whole top of the plant and pegging it down in a trench 2 or 3 inches deep. The usual practice is to plant trees with one-year-old tops in the winter, inclining the trunk at an angle of 30 to 45 degrees from the horizontal. The following winter, after one season's growth, the top is layered. Any branches that cannot be held flat against the bottom of the trench should be removed. In the spring when the new shoots are about 3 inches tall, fine soil is shoveled around their bases, and this process is repeated at intervals until the layered top is covered to a depth of about 6 inches. With more difficult rooting species, all layered parts should be covered about an inch deep with fine soil just before the buds open. In the early winter, after the shoots have grown one season, the soil is drawn away from the layers, and the rooted shoots (fig. 30) are detached. A few of the shoots fail to root each year, and these may be laid down to supplement the original layered tree. The old layers are left uncovered until the following spring, when the program of the previous year is repeated.
Trench layering has been used mostly for the propagation of apple and plum rootstocks. It has been used to only a limited extent in California.

For filberts, suckers from fairly large trees are usually trench-layered, instead of the tops of young trees.

Air layering (pot layering or Chinese layering [marcottage]). This is an ancient method, sometimes used in propagating certain plants that are difficult to start as cuttings and that have an upright growth habit not adaptable to the other types of layering. Although certain varieties of the fig, lichee, persimmon, crabapple, highbush blueberry, and plum have been propagated in this manner, it is not used commercially in California. In the modern procedure of air layering, a ball of some moisture-holding material, such as peat moss or sphagnum moss, is placed around a section of a stem and wrapped tightly with polyethylene plastic sheeting (fig. 31). Roots are initiated at this point and grow into the moss.

The layering may be done when growth starts in the spring, on one-yearold wood, or it may be made in midsummer, using partially-mature, current season's growth. In some plants, roots will form during the first summer, but for others a good root system will not develop until the end of the second year.

The layer should be made on shoots $1 / 2$ to 1 inch in diameter, and be placed about 18 inches back from the terminal end. The branch may be girdled at this point by removing a section of bark $1 / 2$ to 1 inch in width, or it may be partially cut through. Root formation may be stimulated by rubbing a root-promoting powder or brushing a concentrated-dip root-promoting solution (see page 49) on the cut surfaces. The slightly damp (not wet) moss is made into a compact ball about 4 inches wide and 6 inches long, placed on the branch and centered over the girdling cut. A sheet of polyethylene, marketed commercially for 
this purpose as Airwrap, is wrapped securely about the ball and tied at each end. Electrical tape makes a satisfactory tying material as it can be lapped at the upper end to keep rain from seeping

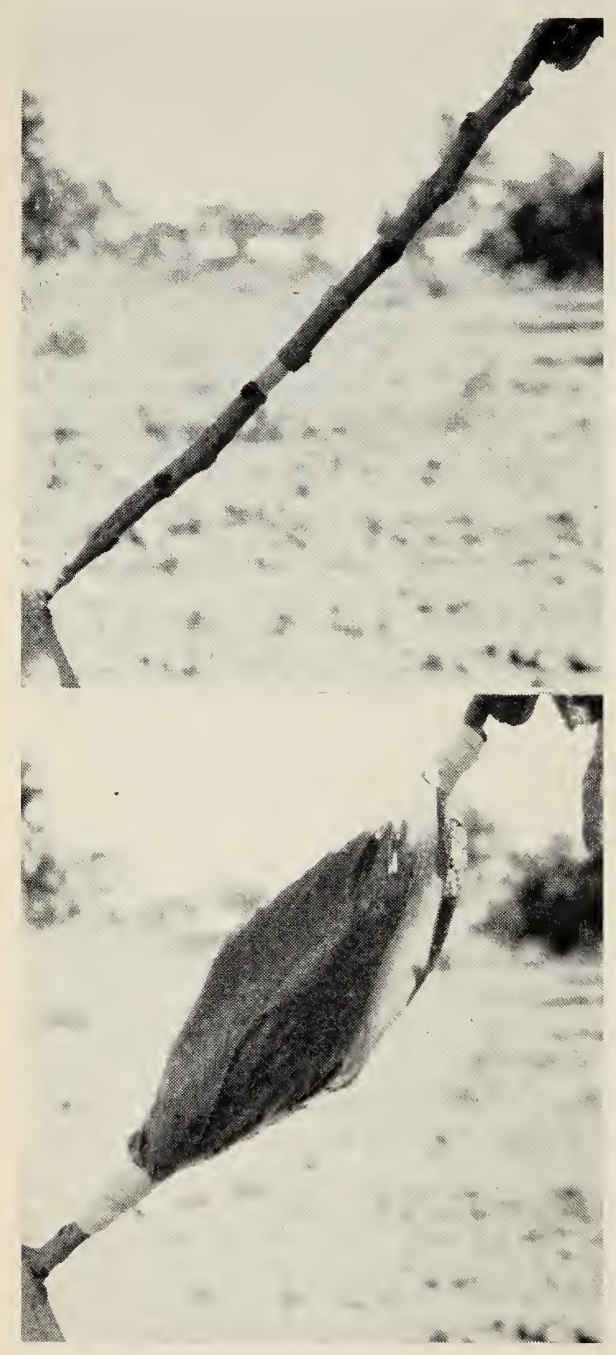

Fig. 31. Preparing an air layer on a fig branch. Above: a 1-inch girdling cut is made around stem just below point where rooting is to take place; below, girdled section is covered with ball of damp, shredded sphagnum moss wrapped with a sheet of polyethylene plastic. Ends are tied with tape wrapped to keep rain from getting under plastic covering. down the branch into the layer. The plastic should be lapped on the underside so that rain does not penetrate and wet the moss excessively. This would cause the bark to rot. No further attention is needed until roots are formed, as seen through the plastic. Generally it is unnecessary to add water since the polyethylene effectively prevents water loss.

After a substantial root system has developed, the branch is cut off just below the ball of moss, the polyethylene is removed, and the layer can be planted. (For deciduous species, removal should be delayed until the dormant season when the layer can be more safely removed.) The ball of moss containing the roots should not be disturbed. Some of the leaves must be removed and the new plant held for a time under cool, humid conditions until it becomes re-established.

\section{RUNNERS}

This method of propagation is a natural type of layering. Runners of the strawberry, which is propagated in this manner, root at every other node, or joint, without assistance if the soil is kept moist (fig. 32). The buds at the rooted nodes send out leaves, thus forming a new plant which, in turn, produces runners and additional runner plants. A single strawberry plant may produce one hundred or more runner plants in one season.

Some everbearing strawberry varieties, such as the Rockhill, seldom produce runners, and must be propagated by dividing the crown into several pieces, each capable of developing into a new plant.

\section{CUTTINGS}

Propagation by cuttings consists of placing a detached piece of the mother plant, such as a stem, root, or leaf, under conditions favorable for root and shoot development. Stem cuttings are the most 


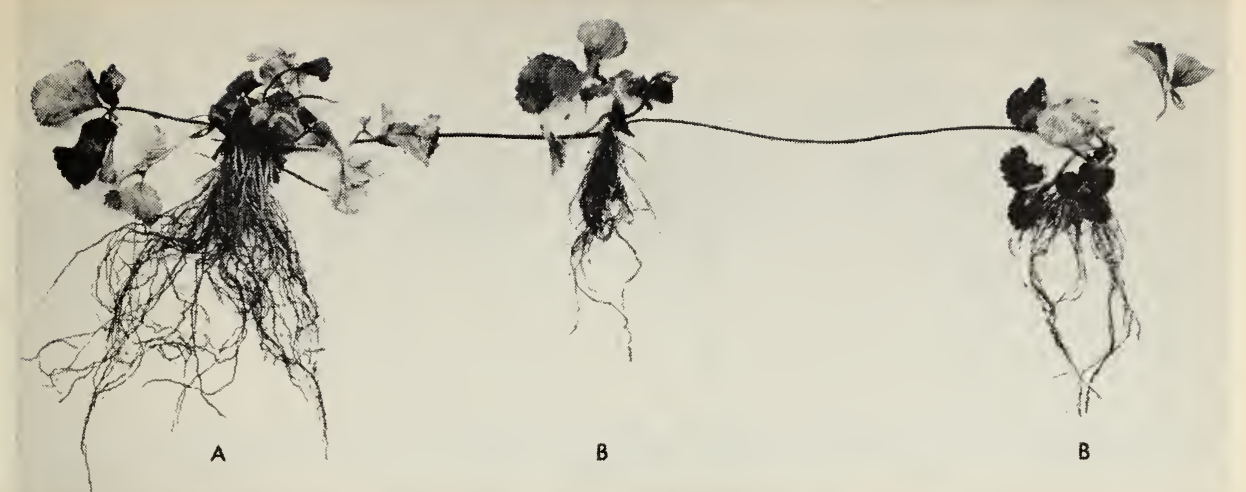

Fig. 32. Propagation of strawberry plants by runners. A, parent plant; B, new plants formed at nodes, or joints. New plants that are produced occur only at every other node.

important, and include the hardwood, semihardwood, and softwood types.

Hardwood cuttings. These consist of sections of the stem usually taken from the previous season's growth although with some species, such as the fig and olive, wood up to two or three years old can be used. For deciduous species, the cuttings are made after the leaves drop, from late fall to early spring. The length of the cuttings varies with the species, ranging from 5 to 15 inches. Each cutting should include at least two nodes. Figure 33 shows some typical examples. Roots ordinarily arise in the vicinity of the lower node, or nodes, while the shoot originates from one of the uppermost buds. In species with short internodes it is immaterial where the cuts are made in relation to the nodes, but if the internodes are long, the basal cut should be about $1 / 2$ inch below a node and the top cut about 1 inch above a node.

A number of varieties of fruit species are propagated commercially by hardwood cuttings and are thus grown "on their own roots." No graft or bud union is involved. These are varieties of the grape, currant, gooseberry, fig, quince, pomegranate, and olive. In addition, a number of rootstocks are propagated in this manner, to be budded or grafted later to a named fruit variety. These include certain plum rootstocks, such as
Myrobalan 29 and Marianna; nematodeand phylloxera-resistant grape rootstocks; types of the quince used as a dwarfing stock for pears; and certain clonal apple rootstocks.

There are several methods of handling hardwood cuttings of deciduous fruit species. The cutting material may be gathered in the fall-about mid-November in California-made into cuttings, and planted immediately. Better rooting of some plants is more often obtained with fall planting than with spring planting, especially in regions with mild winters. In areas with severe winters, cold damage may occur to fall-planted cuttings, and freezing and thawing of the soil may cause the cuttings to heave out of the ground. In addition, rodent injury during winter may be a problem. Even in areas where winters are mild, weed growth in the nursery during winter may require expensive hand weeding in the spring.

Another method commonly used is to prepare the cuttings in late fall or early winter and store them in callusing beds, for planting in the nursery row in early spring. The bundles of cuttings may be packed in some moist material, such as sawdust, shingle tow, or peat moss, in large boxes, and kept in an unheated, outdoor building or a cool cellar until planting time. Temperatures of $40^{\circ}$ to $60^{\circ} \mathrm{F}$ are desirable. 
Another method widely used is to bury the bundles of cuttings in a well-drained, outdoor pit in the soil. The bundles are placed vertically, and inverted-that is, the basal ends of the cuttings are toward the top of the pit and the terminal ends are at the bottom. The soil is then packed loosely around the bundles and is filled in over the base of the cuttings for several inches. Inverting the cuttings places the basal ends nearer the surface where the soil is warmed by the sun. The increased temperature promotes development of roots. The terminal ends being buried more deeply, would presumably be cooler. This has the desirable effect of retarding the activity of the buds.

Watch stored cuttings in any type of callusing bed closely, especially with the coming of warm spring days. If root and shoot activity appears, remove the cuttings immediately and plant them.

Another common practice, especially in areas with mild winter climates, is to gather the cutting material in late winter - but before bud activity begins-prepare the cuttings, and plant them in the nursery row immediately. This is only possible at times during the winter when the soil is sufficiently dry to permit such planting.

Where cold storage facilities are available, cutting material may be gathered at any time during the winter, wrapped in packages containing some moistureholding material, such as peat moss or sphagnum moss, and held at $32^{\circ} \mathrm{F}$ until spring. At that time the cuttings are made and planted immediately.

It is advantageous, with some species, to treat hardwood cuttings with a root-

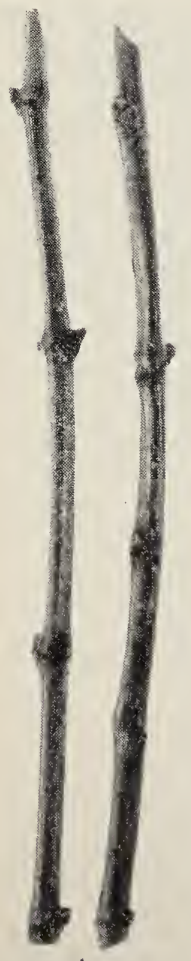

A

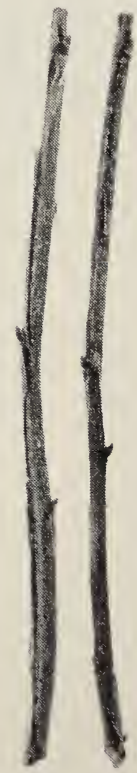

B

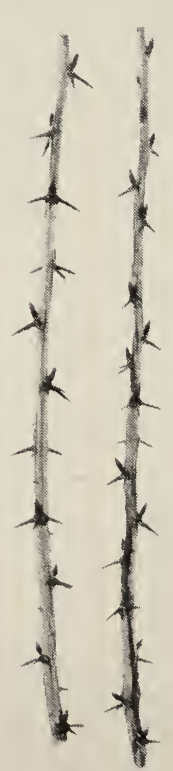

C

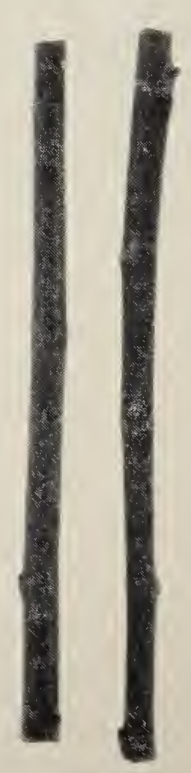

D

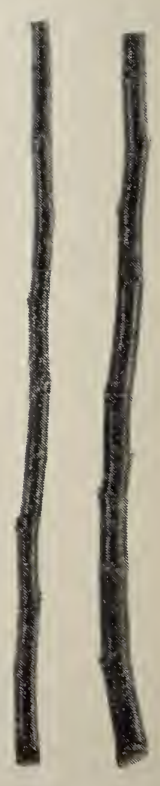

E

Fig. 33. Typical examples of hardwood cuttings. A, grape; B, currant; C, gooseberry; $D$, fig; $E$, quince. 


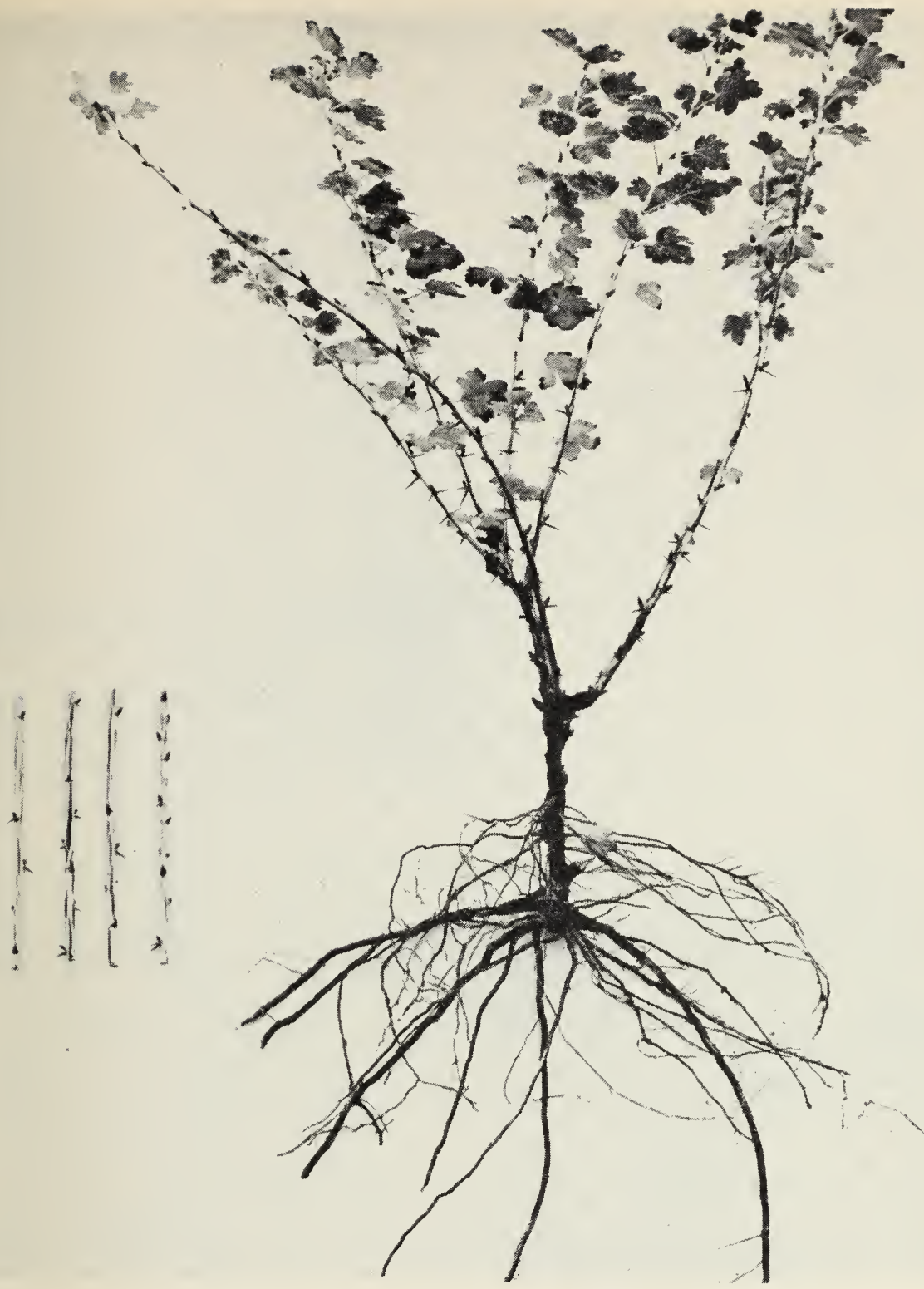

Fig. 34. Left, typical gooseberry cuttings; right, a rooted gooseberry cutting after a year's growth.

promoting chemical before planting (see page 48 ).

As a rule, cuttings are so planted that only one bud is above the ground level, and are placed 2 to 3 inches apart in the nursery row. Figure 34 shows typical gooseberry cuttings before rooting, and a similar rooted cutting after a year's growth.
Semihardwood cuttings. This is a type of stem cutting used in propagating certain kinds of broad-leaved evergreens. The olive is propagated commercially in this manner. Other fruit plants which can be propagated by semihardwood cuttings, although not commercially, include certain citrus species, macadamia, and some avocados. 
These are leafy cuttings which must be rooted under conditions of high humidity, such as glass-enclosed propagating cases or mist propagating beds (see page 45). Semihardwood cuttings can ordinarily be rooted at any time of year, but for those plants which have distinct flushes of growth, it is best to take the cuttings following a period of growth activity after the wood has become partially matured.

Rooting of semihardwood cuttings is sometimes markedly promoted by treat. ments with root-promoting "hormones" (see page 48).

Softwood cuttings. These are leafy stem cuttings made from young, succulent spring growth. Although not used commercially, softwood cuttings of a number of fruit species can be rooted if they are started in mist propagating beds (see page 45) and treated with rootpromoting "hormones" (see page 48). Cuttings which have been rooted in this manner include some varieties of the peach, pear, plum, apple, apricot, cherry, walnut, and grape. In fact, a number of plants considered to be very difficult to propagate by cuttings can be started by using softwood cuttings under mist.

Root cuttings. These are small sections of roots which, when planted, produce a new shoot system and a renewal of growth of the existing root piece. Success is more likely with root cuttings if they are taken from young plants, not over two or three years old. Plants which produce suckers from the roots ordinarily can be propagated readily by root cuttings. Fruit species started in this manner include the red raspberry, trailing and upright blackberries, quince, and some apple rootstocks.

The cuttings can be made from roots of various sizes, even very small roots. They are cut into sections 2 to 4 inches long, and may be planted either horizontally, about 2 inches deep in the nursery row, or vertically with the top just below the surface of the soil. Red raspberry and

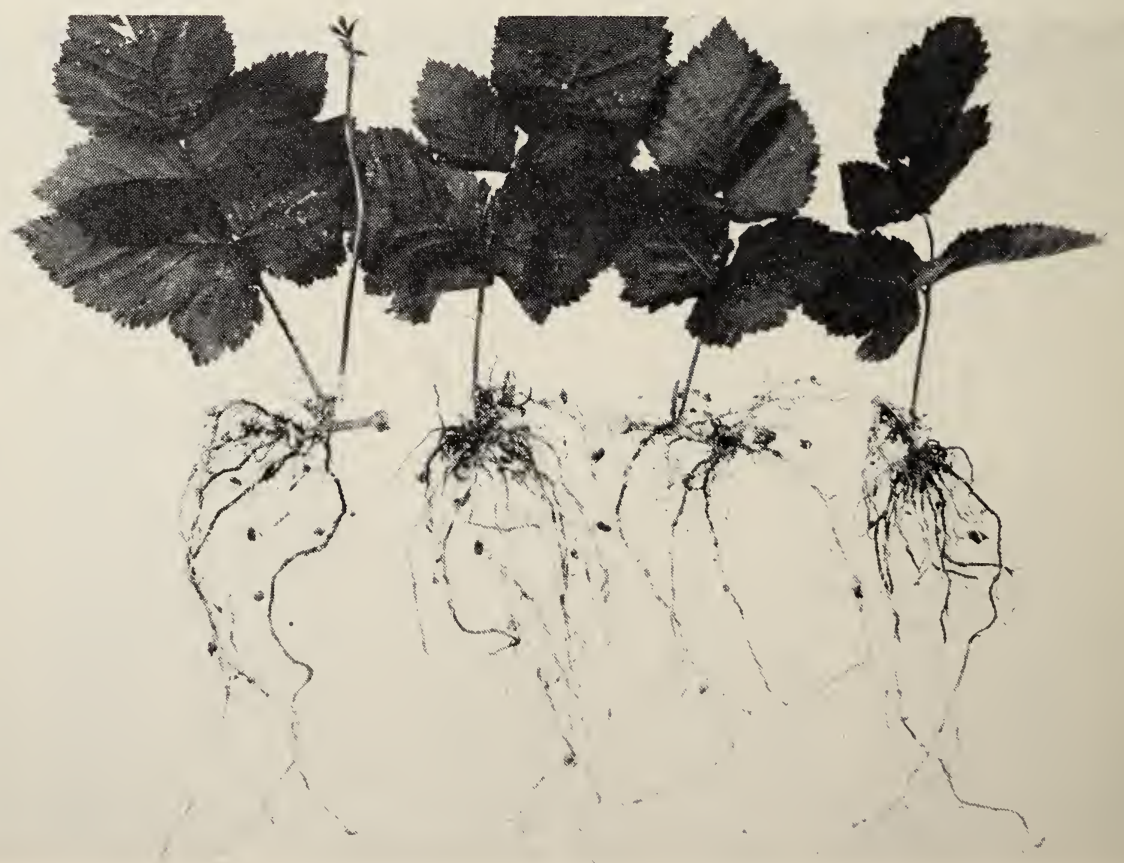

Fig. 35. Boysenberry leaf-bud cuttings. 
blackberry root cuttings are ordinarily planted horizontally. In vertical planting, the end of the root piece which was nearest the crown of the plant should always be up. The best time to take the cuttings is in late winter or early spring before growth starts. They may be made and planted immediately, or stored in a cool, moist callusing bed until they are planted in the spring.

Leaf-bud cuttings. This type of cutting consists of a leaf blade and petiole, together with a short section of the stem to which the leaf is attached, and includes the axillary bud at the base of the petiole. As with any type of leafy cutting, leafbud cuttings must be rooted under high humidity conditions, such as a glasscovered frame or under mist. Black raspberries and the various types of blackberries (fig. 35) can be started in this manner. The red raspberry, however, apparently cannot be propagated by this type of cutting.

\section{ROOTING MEDIA}

Hardwood cuttings, without leaves, are best planted in a fertile, sandy loam soil free of nematodes and other pests, such as crown gall or oak root fungus. A sandy-type soil is desirable since it is generally well aerated-a condition that promotes good rooting of the cuttings. In addition, the soil can be worked soon after rains, facilitating planting and digging operations.

Leafy types of cuttings, started in special propagating beds or frames, require a rooting medium that is well aerated, has good drainage yet holds moisture fairly well, and is free of decaying leaves, twigs, and other organic matter which would harbor diseaseproducing organisms.

Several materials are widely used for rooting media-all giving satisfactory results.

Sand. This is the most common material used for rooting cuttings. A medium grade washed sand, such as that used in the building trade, is the most suitable. Sand has a rather poor water-holding capacity, and requires frequent watering.

Sand-peat moss mixture. This excellent and widely used rooting medium can be combined in various proportions. The peat moss compensates for the poor water-holding capacity of the sand. Quite often a more desirable, fibrous type of root system forms on cuttings in this mixture than is the case in straight sand. Peat moss alone is sometimes used as a rooting medium for acid-requiring plants.

Vermiculite. This material is useful as a rooting medium and is available in several particle sizes. It is a micaceous mineral-chemically, a hydrated magnesium-aluminum-iron silicate-which is expanded by high temperatures to form porous, light weight, sterile particles with a high water-holding capacity. Vermiculite should not be compressed in any way when it is wet since this will destroy its desirable porous structure. Mixtures of vermiculite and sand or vermiculite and perlite (described below) are very satisfactory rooting media, especially in mist propagating beds (see page 46).

Perlite. This is a gray-white material of volcanic origin which has proved useful for rooting cuttings, especially when mixed with vermiculite. It is very light in weight but has a good water-holding capacity, and is practically sterile as a result of the high processing temperatures.

\section{MIST PROPAGATION FOR LEAFY CUTTINGS}

The practice of rooting cuttings under water mist sprays (fig. 36) not only keeps the humidity around the cuttings at a high level, but also lowers the temperature of the leaves, thus helping to reduce undesirable water loss. Ordinary propagation beds can be used in setting up mist equipment, either in the green- 
house, for summer and winter use, or outdoors in a lathhouse or in the open sun, for use during the warmer months. Nozzles over the beds are spaced to produce a fine, foglike spray that completely covers the bed.

Intermittent mist seems to be more satisfactory for most plants than does continuous mist. Only enough water to keep a film on the leaves is necessary. Applications of water in excess of this seem to be of no value, and tend to reduce the temperature of the rooting medium to undesirably low levels. The best practice for most plants is to apply the mist only during the daylight hours, and then only intermittently. The on-andoff intervals can be short, with the mist allowed to wet the leaves thoroughly, then being shut off until the leaves start to dry. Various automatic devices are used for controlling the water.
Several types of spray nozzles are available; two commonly used ones are the oil burner, whirling-action type, and the deflection type. The oil burner nozzle is inexpensive, produces an evenlydistributed, fine spray, and uses a relatively small amount of water. The mist is produced in this nozzle by water passing through small grooves set at an angle to each other.

The deflection nozzle develops a mist by means of a fine stream of water striking a flat surface. The larger aperture used in this type greatly reduces clogging but uses considerably more water. This nozzle usually covers a greater area than the oil burner type so that fewer need be used.

There are several methods of placing the water pipes to which the nozzles are attached. One is to lay the main feeder pipe down the center of the bed below,

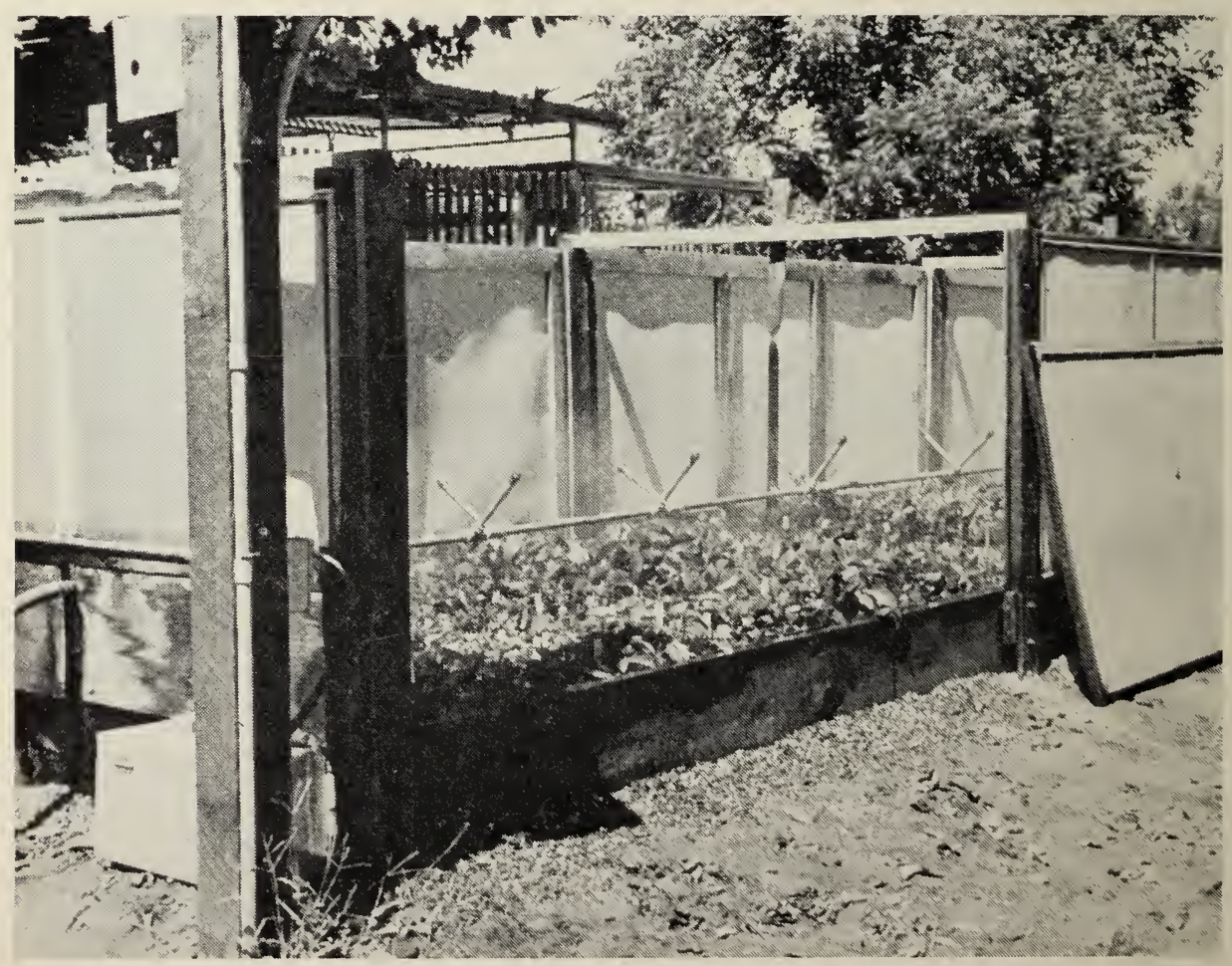

Fig. 36. Out-of-doors mist propagating bed. Nozzles should be spaced close enough together that leaves of all cuttings are wet. Frame around bed keeps strong winds from blowing mist away from cuttings. 


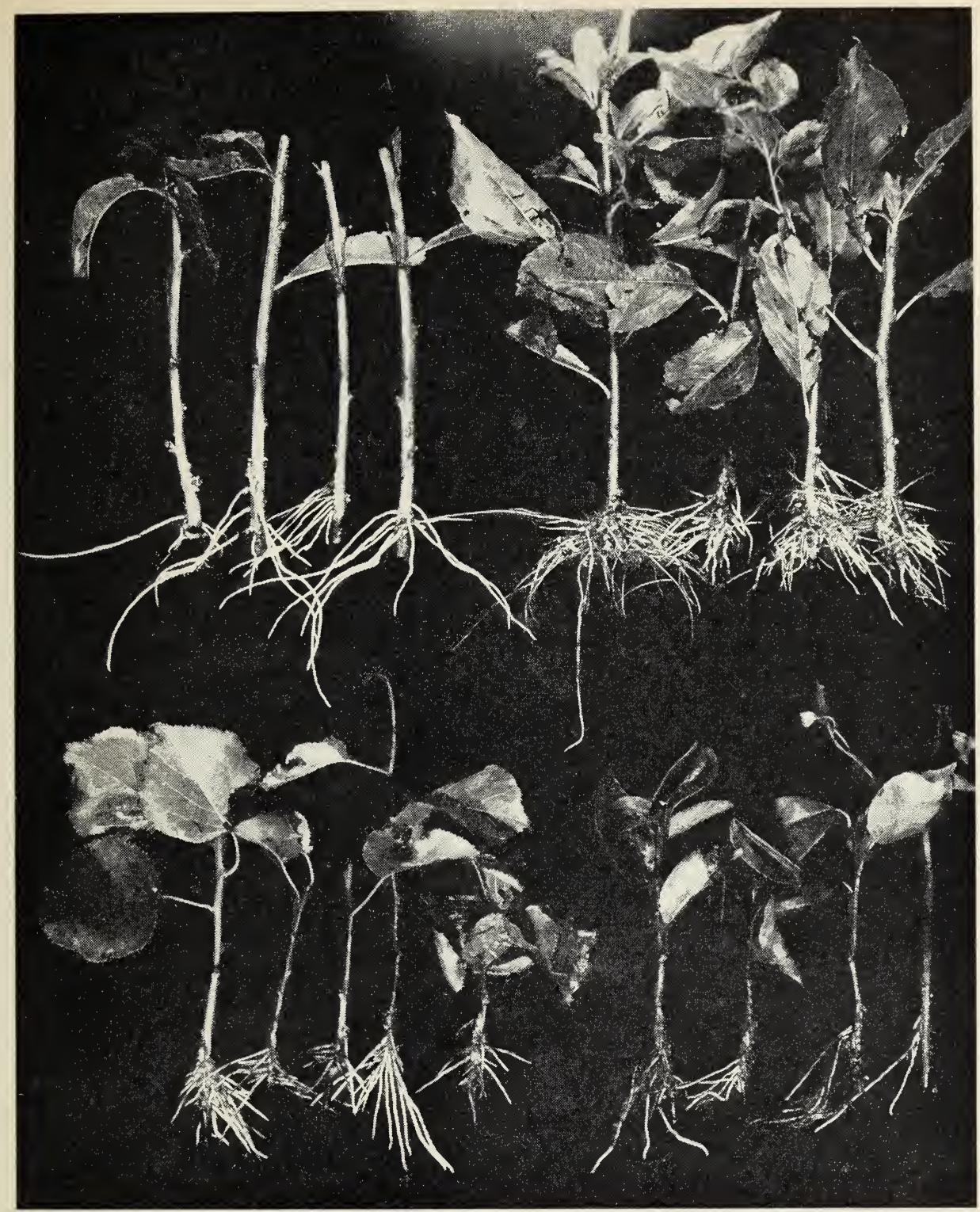

Fig. 37. Examples of cuttings of difficult-to-root fruit species that were treated with a root-promoting substance (indolebutyric acid) and rooted under mist. Top left, Fay Elberta peach; top right, Santa Rosa plum. Lower left, Tilton apricot; lower right, Bartlett pear.

at, or above the surface of the rooting medium, with the nozzles at the end of risers from this pipe. This method eliminates dripping because excess water runs back down the riser pipe. Another method is to place the feeder pipe well above the cuttings - either one pipe down the center of the bed or two pipes, one along each side-with the nozzles directed downward into the bed. Whatever arrangement is used, the nozzles should be placed close enough together and the 
water pressure should be high enough so that the entire bed is completely under the mist. Rooting is likely to be unsatisfactory unless the mist actually wets the leaves.

In outdoor installations some type of protection is usually necessary around the bed to keep strong winds from blowing the mist away and drying out the cuttings.

The frequent operation of the water line to supply an intermittent mist requires the use of an electrically-operated solenoid valve, preferably the normally open type. With this valve, a power failure would simply mean a continuous mist. With a normally closed solenoid, on the other hand, a power failure would cut off the mist entirely. In a bed in the open sun, this could soon result in the death of the cuttings.

An electrically-operated control uses two timers acting together. One timer turns the entire system on in the morning and off at night. The second timer operates the system during the daylight hours to produce an intermittent mist at any desired combination of timing intervals-about 40 seconds on and 60 seconds off is generally satisfactory. This type of control mechanism is relatively foolproof, and while it does not automatically compensate for variations in humidity conditions, it can be adjusted closely enough to give entirely satisfactory results.

Various difficulties often arise in operating a mist propagating bed. One of these is the lack of sufficient water pressure to operate the nozzles properly. This can be overcome by installing a small, electrically-operated rotary booster pump between the water source and the solenoid valve. If there is much sand in the water, it is advisable to install filters in the supply line to reduce clogging of the nozzles.

In propagating cuttings under mist it is essential that a well-drained rooting medium, such as sand or vermiculite, be used. In addition, the bed should either be raised or equipped with drainage tile to provide for quick removal of excess water.

Once the cuttings are rooted, they should be moved promptly from the very moist conditions of the mist to a drier environment but this must be done carefully. One way of doing this is to withhold the mist gradually-decreasing the on periods and increasing the off periods - until the cuttings are able to survive without the mist. The rooted cuttings may then be potted or left in the rooting medium until the dormant season when it is safer to dig them.

Mist propagation permits the use of soft, succulent, fast-growing cutting material, taken early in the season, which is often more likely to root than is more mature hardened wood taken later in the season (fig. 37). This technique is not as yet used in the commercial propagation of most fruit plants.

\section{USE OF GROWTH REGULATORS IN ROOTING CUTTINGS}

Some chemicals, such as indolebutyric acid and naphthaleneacetic acid, will, under certain conditions, promote root initiation on hardwood, semihardwood, and softwood stem cuttings as well as leaf and leaf-bud cuttings. These materials are not recommended for use with root cuttings. While not always effective, in many cases treatments with these materials cause a greater percentage of the cuttings to root, speed root formation, and produce a higher number of roots per cutting. Excessive concentrations for the species can be injurious. Commercial preparations are available, generally in powder form, in which the active ingredients are dispersed in talc. The chemicals can also be obtained as the pure crystals, from which the propagator can prepare his own rooting solutions.

Powder dip method. Powders are available commercially in various 
strengths, and should be used according to directions. The basal ends of the cuttings are dipped into the powder, enough of which generally adheres to be absorbed and effective.

Dilute solution, 24-hour soaking method. Relatively dilute solutions of the chemicals are prepared, in which bundles of the cuttings are soaked for 24 hours, then set in the rooting medium. The basal ends of the cuttings should be immersed in the solution to a depth of $1 / 2$ to 1 inch. The concentrations used vary from 15 to $200 \mathrm{ppm}$ (parts per million), depending upon the species. A strength of 50 to $100 \mathrm{ppm}$ of indolebutyric acid is effective in promoting rooting of softwood, semihardwood, and hardwood cuttings of many plants.

To prepare 1 gallon of an approximate $100-\mathrm{ppm}$ solution of indolebutyric acid, measure a level $1 / 4$ teaspoon of the chemical, dissolve it in a small amount of alcohol, then add to the water, stirring thoroughly.

Concentrated-solution dip method. A rather concentrated solu-
To prepare a 4,000-ppm solution of indolebutyric acid, dissolve a level $1 / 4$ teaspoon of the pure crystals in $3^{1 / 3}$ fluid ounces of 50 per cent alcohol.

tion-500 to $10,000 \mathrm{ppm}$-is prepared in which the basal $1 / 2$ inch of the cuttings is immersed for about 5 seconds. Large bundles of cuttings can be dipped at one time. The cuttings can then be set immediately in the rooting bed. It is always advisable to have fresh basal cuts at the time the cuttings are dipped. For hardwood cuttings, a concentration of about $500 \mathrm{ppm}$ is recommended, but for softwood and semihardwood cuttings, higher concentrations, 4,000 to $6,000 \mathrm{ppm}$, are generally more effective.

\section{SUCKERS}

Red raspberries, upright blackberries, and the Stockton Morello cherry (a rootstock for cherries), are propagated by suckers. The suckers, together with some roots, are removed from the parent plant during the winter (fig. 38).

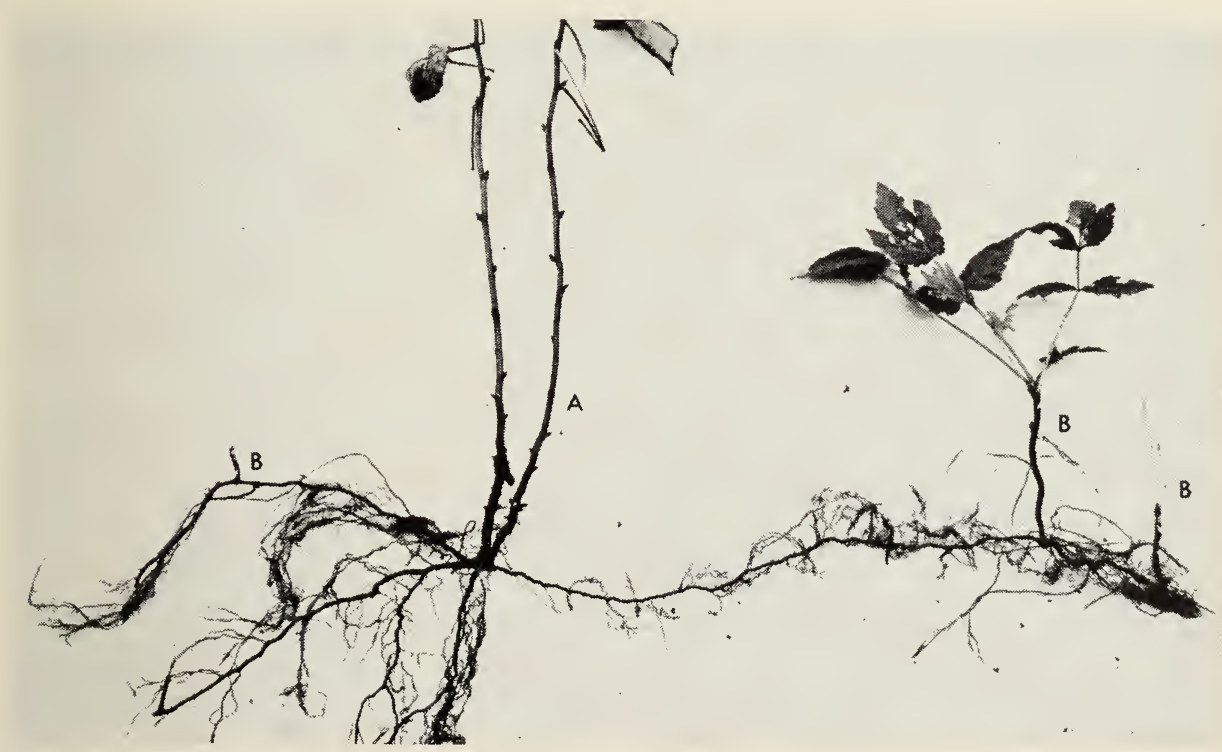

Fig. 38. Suckers of red raspberry. A, parent plant; B, suckers in different stages of development. 


\section{METHODS OF PROPAGATING VARIOUS FRUIT PLANTS}

Quince, fig, grape, currant, gooseberry, olive, and pomegranate, and certain plum rootstocks, such as Myrobalan 29 and Marianna 2624, are easily propagated by hardwood cuttings. Mound, or stool, layering may also be used for quince, currant, and gooseberry. The olive can also be propagated by semihardwood cuttings.

Trailing blackberries, dewberries, and black raspberries are commonly propagated by tip layering, although they can also be started by leaf-bud cuttings.

Red raspberries and upright blackberries are usually propagated by suckers or, if these are not plentiful enough, by root cuttings.

The common varieties of strawberries are easily propagated by runners.

Pear, apple, cherry, peach, nectarine, apricot, almond, and plum are, as a rule, budded on seedling rootstocks, using the $\mathrm{T}$, or shield, method. The work is generally done in the late summer or in the fall, but June or spring budding may also be practiced.

Walnut and pecan are budded on seedling rootstocks by the patch or flute method, or they may be crown-grafted.

Fruit trees are top worked (that is, top grafted or top budded) for various reasons. Sometimes the variety planted may not find a satisfactory market even though the trees are growing well; sometimes seedling trees in orchards or yards may be worked over to established varieties; and sometimes the home orchardist desires to graft or bud a number of varieties or kinds of fruit on one tree. In all these situations, however, the grower should consult table 1 (p. 20) to see which combinations are possible. Small branches of pear, cherry, apple, peach, nectarine, apricot, almond, plum, and fig may be budded in the summer by the $T$, or shield, method. For walnut and pecan, the patch or flute method should be used. Small branches of any common deciduous fruit plant may also be whip- or tongue-grafted-usually in January, February, or March. For branches about 1 inch in diameter, side grafting is reasonably satisfactory.

The cleft graft, bark graft, and sawkerf, or notch, graft are suitable for larger branches up to 3 or 4 inches in diameter. All these methods have given good results with apple, pear, cherry, apricot, almond, plum, persimmon, and fig. Each has advantages and disadvantages which should be considered before making a final selection.

Some propagators have successfully cleft- and saw-kerf-grafted walnuts and pecans, but the average worker has better results year after year with the bark graft. The third method of bark grafting, as described in this circular, is recommended for the walnut and pecan.

Good results cannot be expected when grafting old, weak trees or trees in which growth has been seriously hampered by lack of water, nitrogen, or other necessary materials. This statement applies especially to the peach and the nectarine. Young, vigorous peach and nectarine trees may be successfully cleft-, bark-, or saw-kerf-grafted; but on old, weak trees the grafts will often fail to grow. In general, T, or shield, budding and bark and saw-kerf grafting have given better results with peach and nectarine than has cleft grafting.

Simple layering is at present the most common way of propagating filberts, but trench layering is still used to a certain extent. 
As previously indicated, grapes are propagated by hardwood cuttings. If, however, there are root-knot nematodes or phylloxera in the soil, the desired grape varieties may be whip-grafted before planting in the nursery or chipbudded in the vineyard on resistant rootstocks.
Bridge grafting and inarching are excellent methods for saving injured apple and pear trees and, to a lesser extent, other species.

See Table of Contents, pages 2 and 3 , for sections covering each of the methods mentioned above.

In order that the information in our publications may be more intelligible it is sometimes necessary to use trade names of products or equipment rather than complicated descriptive or chemical identifications. In so doing it is unavoidable in some cases that similar products which are on the market under other trade names may not be cited. No endorsement of named products is intended, nor is criticism implied of similar products which are not mentioned. 
